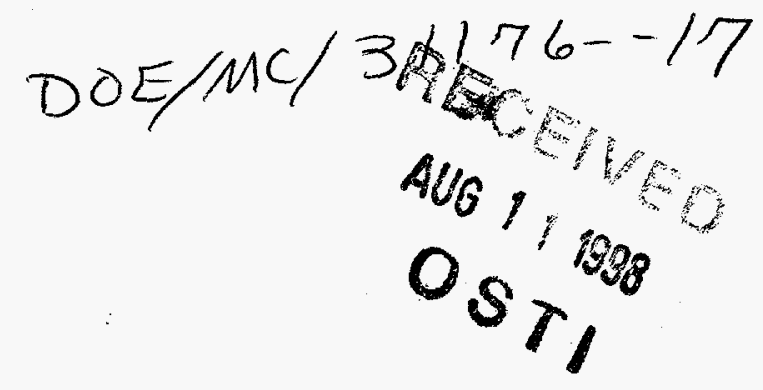

\title{
Utility Advanced Turbine Systems (ATS) Technology Readiness Testing
}

\author{
Technical Progress Report \\ January 1 - March 31, 1998
}

Work Performed Under Contract No.: DE-FC21-95MC31176

For

U.S. Department of Energy

Office of Fossil Energy

Federal Energy Technology Center

P.O. Box 880

Morgantown, West Virginia 26507-0880

By

General Electric Company

Power Generation Engineering

Schenectady, New York 12345

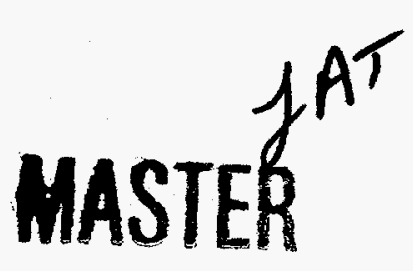




\section{Disclaimer}

This report was prepared as an account of work sponsored by an agency of the United States Government. Neither the United States Government nor any agency thereof, nor any of their employees, makes any warranty, express or implied, or assumes any legal liability or responsibility for the accuracy, completeness, or usefulness of any information, apparatus, product, or process disclosed, or represents that its use would not infringe privately owned rights. Reference herein to any specific commercial product, process, or service by trade name, trademark, manufacturer, or otherwise does not necessarily constitute or imply its endorsement, recommendation, or favoring by the United States Government or any agency thereof. The views and opinions of authors expressed herein do not necessarily state or reflect those of the United States Government or any agency thereof. 


\section{DISCLAIMER}

Portions of this document may be illegible electronic image products. Images are produced from the best available original document. 
ACRONYMS

SECTION 1 EXECUTIVE SUMMARY.

SECTION 2 TECHNICAL PROGRESS REPORTS: CURRENT TASKS …….................. 3

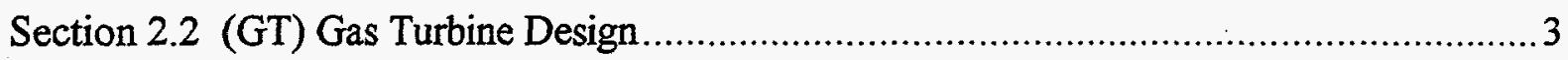

Section 2.2.2 (GTFF) Gas Turbine Flange-to-Flange Design..........................................

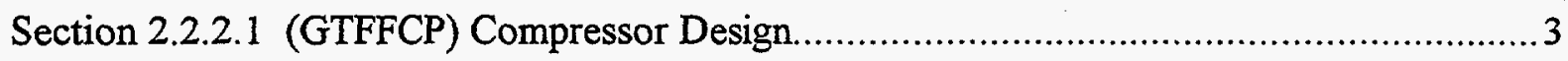

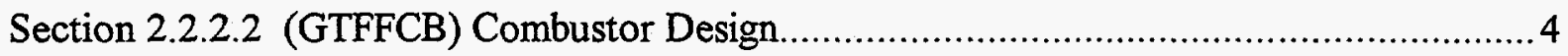

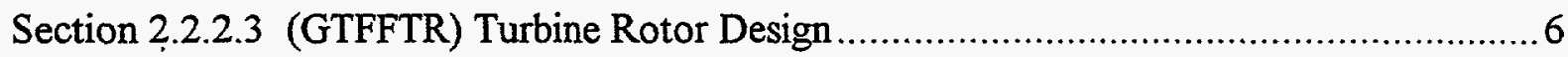

Section 2.2.2.3.3 (GTFFTR) Rotor Steam Circuit Analysis.............................................. 6

Section 2.2.2.3.4 (GTFFTR) Turbine Rotor Shaft Temperature Analysis - \#2 Bearing .......... 7

Section 2.2.2.3.5 (GTFFTB) Bucket Temperature Monitoring........................................... 8

Section 2.2.2.3.6 (GTFFTR) Rotor Component Flow Tests........................................... 9

Section 2.2.2.4 (GTFFTB) Turbine Bucket Design ...................................................... 10

Section 2.2.2.4.4 (GTETIH) Bucket Tip Treatment Heat Transfer................................... 10

Section 2.2.2.4.6 (GTETEH) S1B External Heat Transfer ............................................... 11

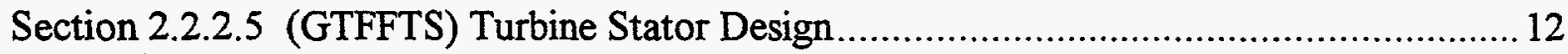

Section 2.2.2.6 (GTFFST) Structures Design ............................................................ 13

Section 2.2.2.7 (GTFFMS) Mechanical System Design................................................ 14

Section 2.2.2.7.1 (GTFFMS) Transient Gas Turbine Cycle Model ................................... 15

Section 2.2.2.8 (GTFFPP) On-Base and External Piping Design ..................................... 17

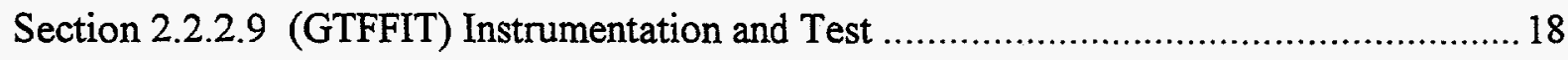

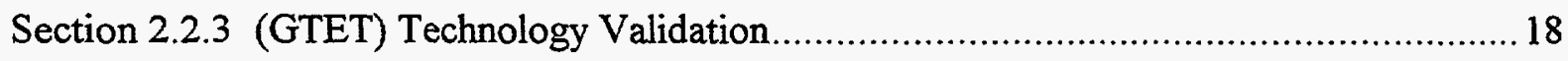

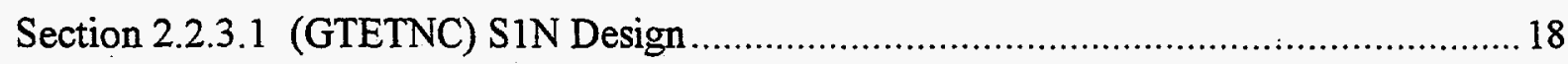

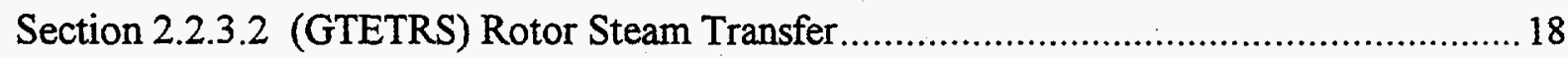

Section 2.2.3.3 (GTETSE) Rotor-Bucket Steam Transfer Spoolie .................................... 19

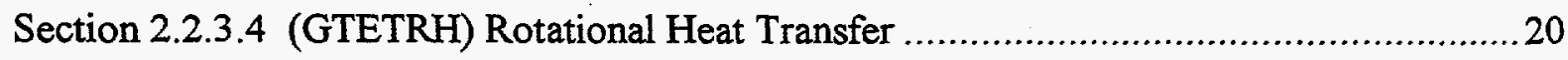

Section 2.2.3.4.1 (GTETRH) Rotational Effects on Bucket Mixing Ribs.........................20

Section 2.2.3.4.3 (GTETRH) - Rotating Trailing Edge Heat Transfer Tests........................ 21

Section 2.2.3.5 (GTETIH) Surface Enhanced Internal Heat Transfer ................................2 21

Section 2.2.3.5.2 (GTETIH) S2B Trailing Edge Heat Transfer Tests...............................21

Section 2.2.3.5.8 (GTETIH) S1N Trailing Edge Heat Transfer Tests................................22

Section 2.2.3.5.11 (GTETIH) Production Airfoil Flow Checks ........................................23 


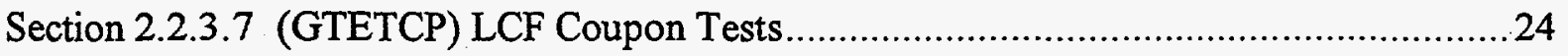

Section 2.2.3.7.1 (GTETCP) LCF and Crack Propagation Rate Tests...............................24

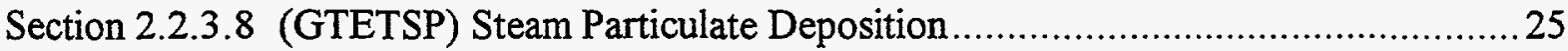

Section 2.2.3.8.1 (GTETSP) Steam Particulate Deposition Rig Testing …........................25

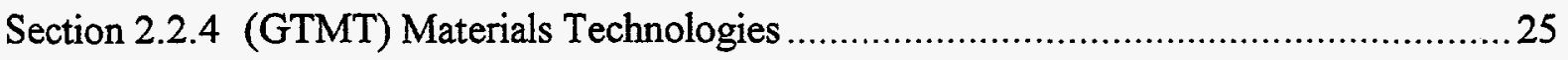

Section 2.2.4.1 (GTMTSE) Steam Effects on Mechanical Properties ...............................25

Section 2.2.4.6 (GTMTCS) Compressor Structural Materials and Processes.......................26

Section 2.2.4.7 (GTMTRF) Turbine Rotor Forging Materials and Processes...................... 27

Section 2.2.4.8 (GTMTRS) Turbine Rotor Spoolies and Transfer Devices Materials

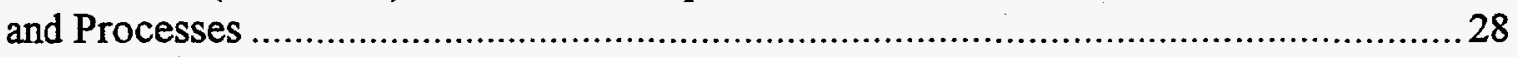

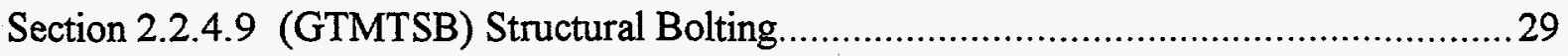

Section 2.2.4.10 (GTMTTA) Turbine Airfoils Materials and Processes..............................29

Section 2:2.4.11 (GTMTCB) Combustion Materials and Processes....................................30

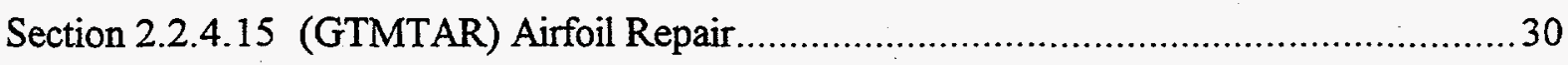

Section 2.2.5 (GTTT) Thermal Barrier Coating Technology ......................................... 31

Section 2.2.5.1 (GTTTSD) Coating System Development ............................................... 31

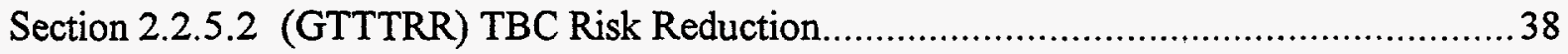

Section 2.2.5.3 (GTTTDD) TBC Design Data and Life Analyses................................... 40

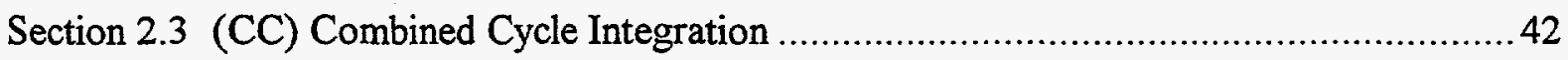

Section 2.3.1 (CCUA) Unit Accessories ............................................................................ 42

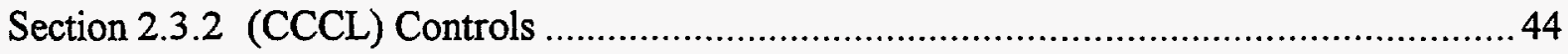

Section 2.3.3 (CCRA) Reliability, Availability, and Maintainability (RAM) Analysis............ 45

Section 2.3.4 (CCSD) Combined Cycle Systems Design .................................................45

Section 2.4 (MF) Manufacturing Equipment and Tooling.................................................46

Section 2.5 (IG) Integrated Gasification and Biomass Fuel..............................................4 47

Section 2.6 (DE) Pre-Commercial Demonstration...........................................................4 47

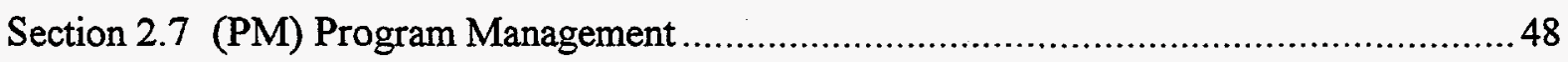

SECTION 2 TECHNICAL PROGRESS REPORTS: COMPLETED TASKS ....................49

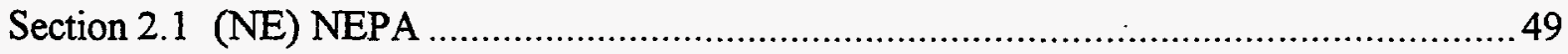

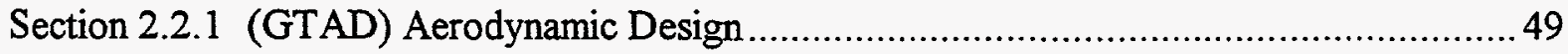

Section 2.2.2.3.1 (GTFFTR) Turbine Rotor Mechanical Analysis ....................................50

Section 2.2.2.3.2 (GTFFTR) Wheel Forging Residual Stress Analysis............................... 50 
Section 2.2.2.4.1 (GTFFTB) S1B and S2B Wheel Dovetail Analysis ...............................51

Section 2.2.2.4.2 (GTFFTB) S3B and S4B Tip Shroud Design Optimization..................... 51

Section 2.2.2.4.3 (GTFFTB) Bucket Wide Grain Sensitivity Analysis ..............................51

Section 2.2.2.4.3.1 (GTFFTB) Bucket Robust Design and Life Assessment....................... 52

Section 2.2.2.4.5 (GTFFTB) S1B and S2B Air/Steam Coolant Transition Analysis............. 52

Section 2.2.2.5.1 (GTFFTS) Turbine Stator Robust Design ............................................. 52

Section 2.2.2.6.1 (GTFFSTEF) Exhaust Diffuser Performance .......................................53

Section 2.2.2.6.2 (GTFFST) Steam Box CFD Analysis................................................... 54

Section 2.2.3.1.1 (GTETNC) Nozzle Cascade CFD Analysis .........................................5 55

Section 2.2.3.1.2 (GTETEH) Combustion-Generated Flow Effects on Heat Transfer........... 55

Section 2.2.3.4.2 (GTETRH) Bucket Cooling Circuit Rotational Pressure Drop Test .........55

Section 2.2.3.5.1 (GTETS2NHT) S2N Trailing Edge Flow Test.....................................56

Section 2.2.3.5.3 (GTETIH) S1N Outer Band Liquid Crystal Heat Transfer Tests .............. 56

Section 2.2.3.5.4 (GTETIH) S1N Convex Cavity Heat Transfer Tests..............................57

Section 2.2.3.5.5 (GTETIH) Bucket Tip Closed Circuit Cooling ….................................. 58

Section 2.2.3.5.6 (GTETLE) Bucket Leading Edge Heat Transfer Testing ........................58

Section 2.2.3.5.7 (GTETIH) SIN Surface Enhanced Internal Heat Transfer .......................58

Section 2.2.3.5.9 (GTETBKHT) High Reynolds Number Turbulator Static Heat

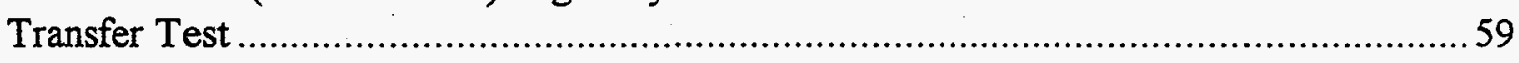

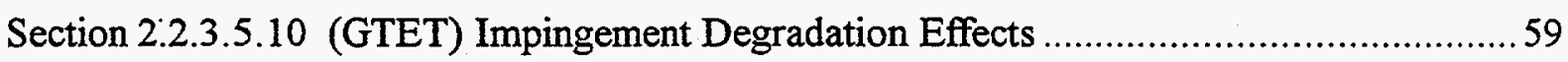

Section 2.2.3.6 (GTETEH) Surface Roughness and Combustor-Generated Flow Effects

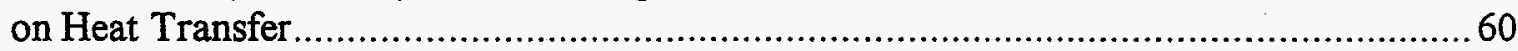

Section 2.2.3.6.1 (GTETEH) SIN Heat Transfer for Production Aero with TBC Spall

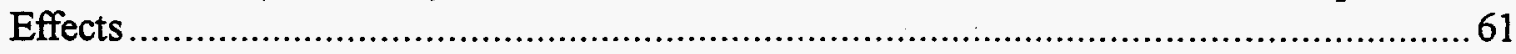

Section 2.2.3.6.2 (GTETEH) Surface Roughness Effects on Heat Transfer........................61

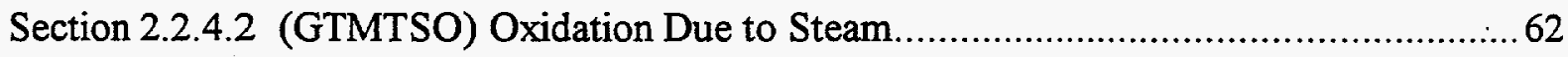

Section 2.2.4.3 (GTMTCE) Corrosion Rate Evaluations of Airfoil Overlay Coatings..........62

Section 2.2.4.4 (GTMTBV) Compressor Blades and Vanes Materials and Processes ..........63

Section 2.2.4.5 (GTMTVG) Compressor Variable Guide Vane System Design Support

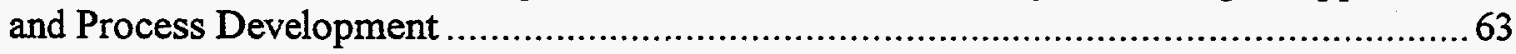

Section 2.2.4.12 (GTMTST) Turbine Structures Materials and Processes .......................... 64

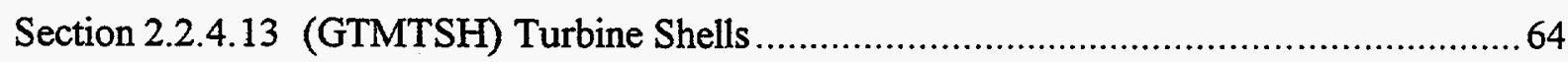

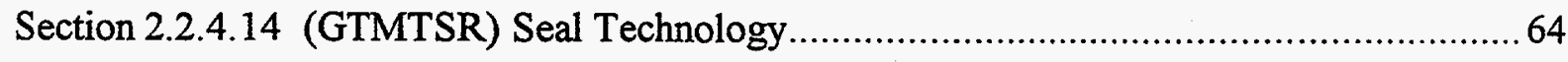


Section 2.2.4.14.1 (GTFFTSESV) Hot Gas Path and Transition Piece Cloth Seals .............65

Section 2.2.4.14.2 (GTETBS) Steam Gland Brush Seals.............................................. 65

Section 2.2.5.3.1 (GTFFTB) Bucket TBC Roughness and Spall Characterization ...............66

\section{LIST OF FIGURES}

Figure 1-1. Schematic of $\mathrm{H}$ machine cross section. .2 


\section{ACRONYMS}

ANSYS - finite element software

APS - air plasma spray

CAD - computer-aided design

CDC - compressor discharge case or casing

CFD - computational fluid dynamics

CMAS - calcium-magnesium-aluminumsilicate

CMM - Coordinate measuring machine

CNC - computer numeric control

CRD - GE Corporate Research and

Development

CSMP - Coordination through Short Motion Programming

CTP - critical-to-process

CTQ - critical-to-quality

DLN - dry low NOX

DOE - U.S. Department of Energy

DTC - design to cost

EDR - electronic data release

EPRI - Electric Power Research Institute

FEA - finite element analysis

FETC - Federal Energy Technology

Center

FMEA - failure modes effects analysis

$F P Q$ - first piece qualification

FSFL - full speed, full load

FSNL - full speed, no load

GEAE - GE Aircraft Engines

GEPS - GE Power Systems
GTCC - gas turbine combined cycle

HCF - high cycle fatigue

HRSG - heat recovery steam generator

HVOF - high velocity oxy-fuel

IGCC - integrated gasification combined cycle

IR - infrared

IT - Inverse Time

KCP - key control parameter

KNP - key noise parameter

LCF - low cycle fatigue

LCVT - liquid crystal video thermography

NDE - nondestructive evaluation

NEPA - National Environmental Policy Act

NPI - New Product Introduction

QFD - quality function deployment

RAM - reliability, availability, and maintainability

SSPM - steady state performance model

STP - Segment Time Programming

TBC - thermal barrier coating

TBO - time-between-outages

TCP - Tool Center Point

TDM - thermal dynamic model

TMF - thermomechanical fatigue

UAB - Utility Advisory Board

VGV - variable guide vane

VSV - variable stator vane

YFT - fluids analysis software 


\section{SECTION 1 EXECUTIVE SUMMARY}

The overall objective of the Advanced Turbine System (ATS) Phase 3 Cooperative Agreement between GE and the U.S. Department of Energy (DOE) is the development of the GE 7H and 9H combined cycle power systems. The major effort will be expended on detail design. Validation of critical components and technologies will be performed including: hot gas path component testing, sub-scale compressor testing, steam purity test trials, and rotational heat transfer confirmation testing. Processes will be developed to support the manufacture of the first system, which was to have been sited and operated in Phase 4 but will now be sited and operated commercially by GE. This change has resulted from DOE's request to GE for deletion of Phase 4 in favor of a restructured Phase 3 (as Phase 3R) to include full speed, no load (FSNL) testing of the $7 \mathrm{H}$ gas turbine. Technology enhancements that are not required for the first machine design but will be critical for future ATS advances in performance, reliability, and costs will be initiated. Long-term tests of materials to confirm design life predictions will continue. A schematic of the GE $\mathrm{H}$ machine is shown in Figure 1-1.

This report summarizes work accomplished in 1Q98. The most significant accomplishments are listed below:

\section{H-Specific}

- Completed $9 \mathrm{H}$ casing assembly prior to unit rotor installation

- Completed 9H unit rotor (compressor and turbine on a common shaft) assembly

\section{H/7H-common technology}

- Demonstrated significant improvement in TBC application thickness control on replica ATS airfoils

- Installed upgraded eddy current TBC measurement systems at GE Power Systems (GEPS) locations and at machining vendor

- Completed evaluation of prototype nozzle heat transfer cascade test data

- Completed full-scale combustion test stand checkout at GE Aircraft Engines (GEAE)

- Completed testing of combustion system to be used on the 9H FSNL test

- Manufactured test buckets with new TBC for evaluation tests in customer machine

- Incorporated an updated transient gas turbine model into the overall plant simulation model and completed startup simulation

- Modified the gas turbine transient cycle model to simulate FSNL operation

\section{H-specific}

- Generated eight transition piece shapes for finite element analysis (FEA) and computational fluid dynamics (CFD) analyses to determine Design of Experiments response surfaces 


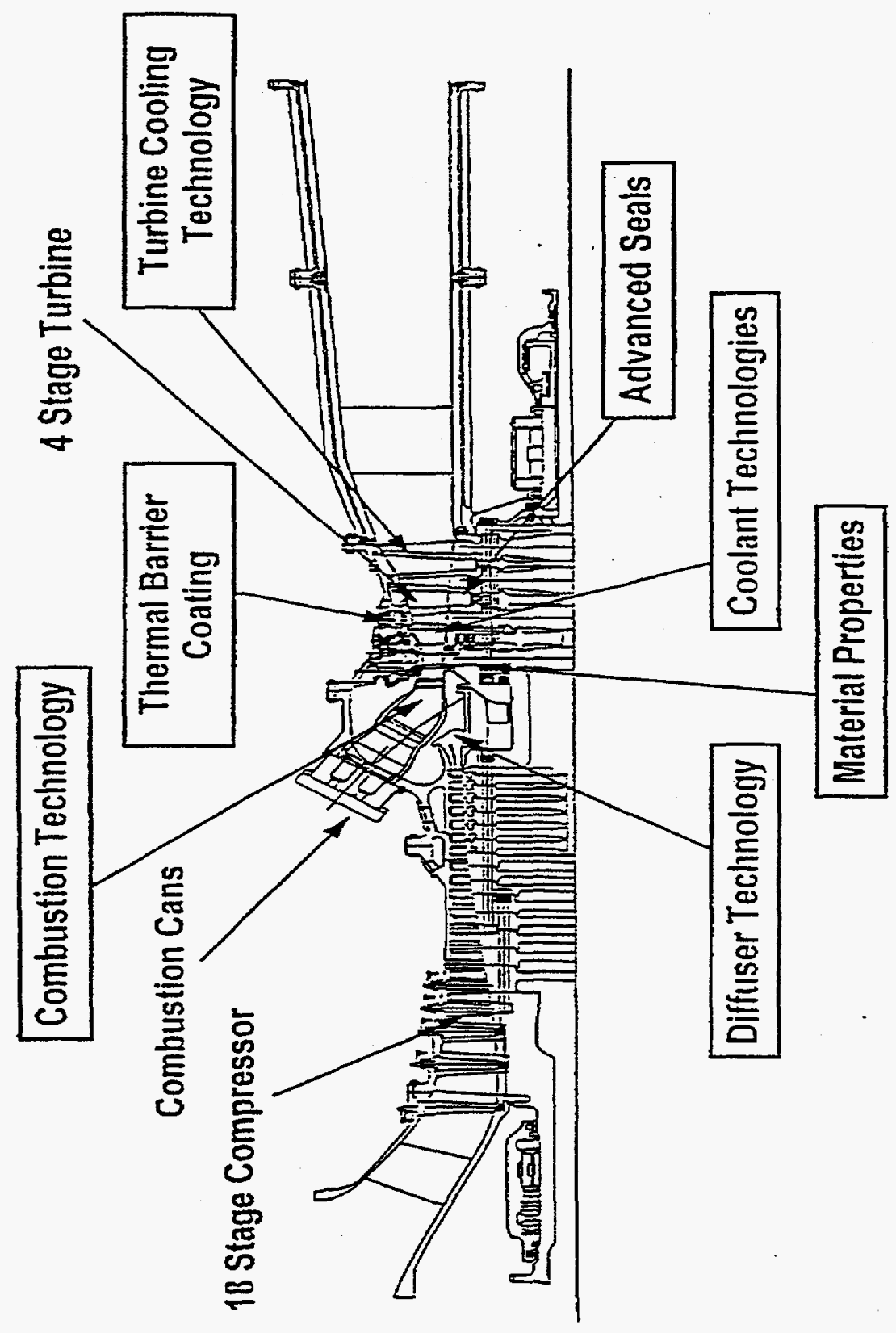

Figure 1-1. Schematic of $\mathrm{H}$ machine cross section 


\section{SECTION 2 TECHNICAL PROGRESS REPORTS: CURRENT TASKS}

\section{Section 2.2 (GT) Gas Turbine Design}

\section{Section 2.2.2 (GTFF) Gas Turbine Flange-to-Flange Design}

\section{Section 2.2.2.1 (GTFFCP) Compressor Design}

\section{Objective}

The objective of this task is to design $7 \mathrm{H}$ and $9 \mathrm{H}$ compressor rotor and stator structures with the goal of achieving high efficiency at lower cost and greater durability by applying proven GEPS heavy-duty use design practices. The designs will be based on the GEAE CF6-80C2 compressor. Transient and steady-state thermomechanical stress analyses will be run to ensure compliance with GEPS life standards. Drawings will be prepared for forgings, castings, machining, and instrumentation for FSNL tests of the first unit on both $9 \mathrm{H}$ and $7 \mathrm{H}$ applications.

\section{Progress for this Quarter}

Unit clearance analysis and component analysis for the $9 \mathrm{H}$ were completed, and all parts lives were calculated to meet product life requirements based on GEPS design practices. Additional lifing based on GEPS product-line lessons learned for compressor rotor components is in process. Design improvements are being made where necessary for delivery of the production unit to test. This life enhancement necessitates changes to the $9 \mathrm{H}$ compressor rotor aft shaft and compressor discharge casing (CDC) inner barrel for full speed, full load (FSFL) preshipment test.

Assembly of the gas turbine unit, including all compressor parts, was completed at the GE Greenville, SC, facility. Rescheduling of the variable stator vane (VSV) system to provide an opportunity to examine a higher flow/power setting during FSNL testing was completed. Component manufacture of new torque shafts and third- and fourth-stage turnbuckle links for the production design and test release was completed. Post-test data reduction from the Rig 2 compressor tests for final aerodynamic performance and aeromechanics issues concluded that (1) this VSV rescheduling has the potential for significant performance benefit and (2) blade aeromechanics should be acceptable for the new setting. This conclusion will be confirmed in FSNL testing in May 1998.

Additional instrumentation (light probes) for aeromechanics was completed on the inlet and compressor case sections of the casings for enhancements to rotor blade aeromechanics evaluation. A producibility and design conference was held, and design changes were recommended for the compressor discharge tri-passage diffuser castings. These changes were initiated for the $7 \mathrm{H}$ production unit to enhance part quality, life, and cost. Similar changes were planned for the $9 \mathrm{H}$ Block 2 design.

The $7 \mathrm{H}$ aerodynamic design was completed for the new airfoil stages $0,1,2,3,14,15,16$, and 17 , with the exception of final incremental changes to R0. Aeromechanics evaluation of the airfoils was completed and met design criteria, with the exception of final incremental changes to R0. A $7 \mathrm{H}$ compressor flowpath incorporating lessons learned on the $9 \mathrm{H}$ 
compressor rig and product unit is now frozen. Initial stress analysis of forward stage blade dovetails was completed prior to setting the flowpath; however, final 3D issues to minimize $\mathrm{R} 0$ dovetail stresses for acceptable life are still being addressed.

\section{Plans for Next Quarter}

With the completion of $9 \mathrm{H}$ unit assembly, work for the $9 \mathrm{H}$ program will focus on initial machine testing (FSNL in May 1998), and providing engineering support for test preparation and data reduction of the instrumented $9 \mathrm{H}$ compressor. $9 \mathrm{H}$ compressor testing will be completed by the end of $2 \mathrm{Q} 98$, with data reduction and evaluation to follow.

The $7 \mathrm{H}$ design work will continue to accelerate during $2 \mathrm{Q} 98$ with release of components needed for sub-scale testing and long-lead-time items for the $7 \mathrm{H}$ product unit. A $7 \mathrm{H}$ compressor concept design review will be completed. Detailed product definition and trade studies to define the basic geometry will be completed. Major compressor components and preliminary design analysis for forging releases of blades and rotors will be completed, as well as initial releases of compressor case castings (e.g., inlet, compressor case, compressor discharge case, and compressor discharge diffuser).

\section{Technology Application}

The compressor design (aerodynamic and mechanical) and rig test results establish the basis for the $7 \mathrm{H}$ and $9 \mathrm{H}$ compressor production hardware.

\section{Section 2.2.2.2 (GTFFCB) Combustor Design}

\section{Objective}

The objective of this task is to design a combustor based on the commercial DLN2 combustion system, with modifications made for improved use of available air, reduced cooling, and greater load turndown capability. This design will be similar for both the $7 \mathrm{H}$ and $9 \mathrm{H}$ machines. It will be configured to ensure the ability to use preheated fuel. Rig testing of full-scale and scaled components will be conducted at $7 \mathrm{H}$ and $9 \mathrm{H}$ cycle conditions. The final configuration will be validated in single-combustor, full-scale tests under full operating conditions.

The premixer-burner design will be optimized to use minimum pressure drop, achieve required fuel/air mixing, maintain stable flame, and resist flashback. The basic design will be developed and evaluated in full-scale single burner tests and then implemented in full-scale combustors. The ability to meet high cycle fatigue (HCF) life goals depends on understanding the effects and interrelationships of all combustion parameters. Existing dynamics models used in parallel with laboratory-scale and full-scale testing will be used to predict combustor dynamic behavior.

Chamber arrangement, casings, cap and liner assemblies, flame detectors, and spark plugs will be designed and analyzed to ensure adequate cooling, mechanical life, and aerodynamic performance. Fuel nozzles will be designed for operation on gas alone or on gas with distillate as a backup fuel. The transition piece will be designed and integrated with the design of the machine mid-section, transition duct cooling, and mounting. 
A full-scale, single-combustor test stand will be designed and fabricated to verify performance of the combustion system. Facility modifications will be made to support the test. These include installation of the test stand, installation of high-temperature stainless steel air piping, an additional air heater, control systems, upgrades to the combustion video system, and tooling.

\section{Progress for this Quarter}

All transition piece assemblies were received from suppliers and installed in the FSNL gas turbine. The remaining combustion subassemblies for the FSNL system were also installed in the unit in preparation for test. In addition, the FSNL combustion system was component tested in the GEAE full-scale combustion development test stand (A2). System performance was as expected.

Shakedown testing was completed in test stand A2. In addition, the FSNL system and the first 9H product combustion system were fully tested and characterized on natural gas fuel. Performance of the product combustion system exceeded expectations in all areas except load range capability for premix operation.

A family of eight $7 \mathrm{H}$ transition piece body shapes was generated in semi-automatic fashion using standard computer-aided design (CAD) software. These shapes were then submitted to computational fluid dynamics (CFD) and finite element analyses (FEA) so that their Design of Experiments response surfaces could be determined.

\section{Plans for Next Quarter}

Development will continue on the swozzle-based product combustion system. (A swozzle is a combined swizzler/nozzle unit.) One primary objective will be to select the length of the combustion system. Operation on distillate fuel with water injection will play a significant role in that determination. Another primary objective will be to extend the load range over which premix operation will be robust.

A decision will be made on the shape of the $7 \mathrm{H}$ transition piece based on the results of the Design of Experiments analyses. The selected shape will be fabricated for cold flow testing to ensure that it will not permit any regions of flow separation.

The FSNL gas turbine test will begin. Post-test inspection of the transition piece seals is expected to yield insight into the performance of the cloth seal system for the transition pieces.

\section{Technology Application}

Design and development of the combustion system is required for the ATS gas turbine to meet the low emissions targets at the high cycle conditions of inlet temperature, pressure, air flow, and outlet temperature, all of which are greater than those of any of GE's developed products. 


\section{Section 2.2.2.3 (GTFFTR) Turbine Rotor Design}

\section{Objective}

The objective of this task is the design of turbine rotor components (wheels, spacers, aft shaft, transition discs, coolant systems, and fastening devices). Transient and steady-state stress analyses will be used to calculate parts lives. Rotor and system vibratory characteristics will be evaluated. The coolant flow circuit for routing the cooling steam to and from buckets will be designed and performance calculated. Test results will be incorporated concurrently. Drawings and specifications will be developed in preparation for manufacturing.

\section{Progress for this Quarter}

The turbine rotor critical feature life was revised with the updated stress information.

Several iterations were made on the turbine rotor secondary flow system. The new secondary flow system will be a flow-through purge system in place of the original mixed flow design. The new system shows potential for improvement in simplicity, performance, rotor behavior, and bolt hole stress. Work is progressing to introduce the new system into the first $9 \mathrm{H}$. machine.

The 9H turbine rotor was stacked and torqued successfully. The unit rotor (compressor and turbine on a common shaft) was completed and installed successfully.

3D thermal mechanical analyses are underway for the 1-2 spacer and the second-stage turbine wheel.

\section{Plans for Next Quarter}

Life analyses for the $9 \mathrm{H}$ marriage joint configuration will continue. The Design of Experiments and conceptual design review for the $7 \mathrm{H}$ turbine rotor will be completed. Detailed life analysis of the $7 \mathrm{H}$ rotor will begin.

\section{Technology Application}

The turbine rotor analysis and design effort defined the basis for the $7 \mathrm{H}$ and $9 \mathrm{H}$ production hardware.

\section{Section 2.2.2.3.3 (GTFFTR) Rotor Steam Circuit Analysis}

\section{Objective}

The objective of this task is to assess rotational and 3D effects on the flow within the rotor steam circuit components whose performance is strongly dependent on these effects. The steam distribution into the buckets, for example, depends on the performance of the manifolds to ensure that the buckets are adequately cooled. Hydraulic losses can be better estimated when 3D effects are considered. The rotational and 3D effects will be assessed using CFD, and the results of the analyses will provide the basis for design modifications if necessary. 


\section{Progress for this Quarter}

At the beginning of $1 \mathrm{Q} 98, \mathrm{CFD}$ analyses of the return manifold revealed a pressure drop that exceeded the allocated losses for the component. Although the flow distribution into the buckets was adequate, the design exhibited high Mach number (around 0.2) recirculation zones that resulted in excessive pressure losses.

Design modifications were implemented that resulted in significant improvement in performance, bringing the component pressure losses near target levels. The flow distribution for the modified design shows a more uniform characteristic.

A design review of the steam distribution system was also conducted in which all CFD analyses of the rotor inlet section, supply endcap and radial tube, supply and return manifold, return radial tube and endcap, and return bore tube were presented. No open items resulted from the review.

\section{Plans for Next quarter}

CFD analyses of the test configuration of the supply manifold will be conducted.

\section{Technology Application}

The results of this task define the hydraulic performance and help guide the design of the overall steam distribution circuit and critical individual components it comprises. Performance predictions of various designs are used in trade-off and optimization studies to select the baseline concept of the overall steam distribution strategy and the specific design of the scroll, the supply and return manifolds, and supply and return bore tube and endcaps.

\section{Section 2.2.2.3.4 (GTFFTR) Turbine Rotor Shaft Temperature Analysis - \#2 Bearing}

\section{Objective}

The objective of this task is to investigate design options that would result in a minimum temperature of the shaft surface in contact with oil and/or air oil mist, and a maximum thermal gradient in the area of the oil seals in the $\# 2$ bearing.

Allowable temperatures in the seal forward of the $9 \mathrm{H}$ turbine $\# 2$ bearing are limited due to the accelerated decomposition of lubricating oil at high temperatures. Thermal gradients are also limited in that uneven thermal expansion of the shaft will adversely affect seal clearances and performance.

\section{Progress for this Quarter}

The detailed lumped fluid element aft shaft thermal analysis iterations were completed. The bearing cooling design was down-selected from several concepts to match the original bearing flow-through concept. An extra piece will be required to incorporate the final design. Iterations are in progress to identify the final fourth-stage/aft wheel shaft (AWS) rabbet configuration. 


\section{Plans for next Quarter}

The $7 \mathrm{H}$ turbine rotor thermal analyses will focus on high rabbet configuration details to match thermal transients.

\section{Technology Application}

All the design options evaluated in this study were considered for ATS turbine rotor design in a detailed follow-up study using a fluid element analysis approach to better simulate the heat transfer boundary conditions in the current modeling effort.

\section{Section 2.2.2.3.5 (GTFFTB) Bucket Temperature Monitoring}

\section{Objective}

The objective of this task is to provide the steam-cooled rotor buckets with protection against a loss-of-steam-coolant event. The protection system will provide a timely signal enabling the turbine to be shut down with minimal damage.

\section{Progress for this Quarter}

The pyrometer system being tested on an F-class gas turbine was recalibrated. The system, including the sight glass window and detector/electronics, was inspected. Preparations were made to install a spectrometer unit in place of the single element detector now being used.

At a second site, preparations are being made to install TBC-coated buckets to determine the effect of this coating on the pyrometer signal.

\section{Plans for Next Quarter}

Pyrometer data from the test site will be analyzed for stability and trends. Additional tests will be performed as necessary to fully evaluate the pyrometer data as a function of time. Tests will also be performed with TBC-coated parts.

\section{Technology Application}

Pyrometers will be used in the ATS gas turbine to monitor steam-cooled turbine blade temperature during operation. This will allow for timely detection of insufficient steam coolant flow into the buckets.

Several other technologies were investigated, such as tracer leaks, vibrational signatures, steam pressures, and steam flowrates, but they were discarded in favor of monitoring the bucket temperatures using pyrometers attached to the outer casing of the turbine with a direct line-of-sight view of the first- and second-stage buckets. Pyrometers have several significant advantages: (1) they respond to the parameter of the buckets that is of most concern, i.e., the temperatures; (2) all the buckets in a stage come into the field of view of a single fixed pyrometer; and (3) the detection system has a rapid response time. 


\section{Section 2.2.2.3.6 (GTFFTR) Rotor Component Flow Tests}

\section{Objective}

The objectives of this task are (1) to experimentally determine loss coefficients vs. Reynolds number for selected components in the rotational steam cooling path; (2) to identify high loss areas for each of these components; and (3) to provide loss data for verifying YFT and CFD models.

Design codes like YFT require that a loss coefficient be input for each node (e.g., elbows, tees, and manifolds) of the flow circuit. Flow handbooks and reports provide loss coefficients for typical plumbing fixtures used in steam path plumbing, but much of the steam circuit contains non-standard nodes for which loss coefficients are not available. This task identifies those non-standard nodes and develops the required loss coefficient data. To provide the data models for each of the non-standard nodes, air flow tests at near atmospheric conditions will be conducted to establish the loss coefficient vs. the Reynolds number for that node. The data from the atmospheric test will then be used to bench-mark a CFD code that will calculate the loss coefficient in steam at gas turbine pressure and temperature and with rotation. The CFD work is reported in Section 2.2.2.3.3.

\section{Progress for this Quarter}

Testing on the supply manifold was completed and data reduction is in progress. Each supply manifold connected the steam supply to six first-stage and six second-stage turbine buckets. Test were conducted to determine both the loss coefficient for the manifold and the uniformity of flow to each bucket. Comparison of the manifold data with CFD results was begun.

A test plan was developed to address other key flow components. A production bore tube will be tested to determine loss coefficient and flow stability performance. The bucket return manifold will be tested to determine loss coefficient and flow uniformity. Several spoolie joints will be tested to determine flow stability characteristics.

\section{Plans for Next Quarter}

Data reduction for the supply manifold will be completed to validate the CFD code.

Test facilities will be modified for bore tube tests scheduled for $3 \mathrm{Q} 98$. These tests will give added confidence that the bore tube will perform as anticipated when installed in the gas turbine.

A return manifold will be ordered so that tests similar to those on the supply manifold can be conducted.

\section{Technology Application}

The results of this task help validate the use of analytical tools such as CFD and YFT for the design of the rotor steam circuit components. In addition, data from these tests will help establish that the performance of these components meets design requirements. Flow distribution, pressure drop, and flow stability will be evaluated. 


\section{Section 2.2.2.4 (GTFFTB) Turbine Bucket Design}

\section{Objective}

The objective of this task is the design of buckets for the four rotating stages. The heat transfer and material databases for steam-cooled first- and second-stage buckets continue to expand and will be integrated concurrently with the design. Cooling passages will be sized consistent with manufacturing practicalities and the bucket life requirements. Flow variation and consistency will affect life calculations and will be considered. Current practices for thermomechanical steady-state and transient analyses, dynamics and vibration analysis (which can deal with anisotropy), and corrosion/oxidation analysis will apply throughout. Drawings and specifications will be developed in preparation for manufacturing.

\section{Progress for this Quarter}

Aerodynamic shapes of the $7 \mathrm{H}$ first-, second-, and third-stage buckets were generated and detailed 3D vibration and stress analyses were performed. 3D analysis was also performed on the fourth-stage bucket to assess the creep life and vibration margins with different materials. Sufficient analysis work was completed to enable the first-stage bucket aerodynamic shape to be frozen.

\section{Plans for Next Quarter}

Detailed analysis of the $7 \mathrm{H}$ buckets will continue with a goal of electronic data releases (EDRs) in 2Q98. Further detailed 3D analysis of the turbine buckets will be performed, and iterations on the aerodynamic shape will be performed as required to enable the aerodynamic shape of the airfoils to be frozen. A series of detailed 3D tip shroud analyses (looking at various configurations) on the aft stage buckets will be performed to determine an acceptable configuration. Analysis will be performed on the individual airfoils to determine the required airfoil tilt and lean to minimize the moment transmitted to the dovetail.

Detail design of the $9 \mathrm{H}$ production components will continue with further transient analysis and design modifications for enhanced producibility.

\section{Technology Application}

The design and development of turbine buckets are required for the ATS turbine to ensure that the buckets deliver power to the turbine shaft and that they meet the stated part life requirements.

\section{Section 2.2.2.4.4 (GTETIH) Bucket Tip Treatment Heat Transfer}

\section{Objective}

The bucket tip regions of the ATS turbine remain a critical design issue affecting both turbine performance and life. Since the blades utilize no external film cooling, a tip design must be verified that minimizes both the tip hot gas leakage and the tip external heat loading, while also providing some shroud rub protection for the internal steam-cooling circuit. Standard squealer tip geometries are thought to provide inadequate rub protection and can be difficult to cool without film, while a plain tip geometry will not provide adequate leakage sealing. 
This task continues design verification and design improvement for the first- and second-stage blade tips. A Blade Tip Heat Transfer Cascade will be used with new or modified blade tip geometries to design and verify the appropriate tip heat transfer and seal arrangements in conjunction with manufacturing and cooling requirements. Specifically, this task will determine the external heat transfer coefficient distributions on the blade tip and on the airfoil surface near the blade tip using transient liquid crystal techniques in a blade tip cascade.

\section{Progress for this Quarter}

The bucket tip test model was redesigned to improve test thermal boundary conditions. The previous tip model used a solid acrylic piece of the appropriate aerodynamic shape, which involved an unknown level of heat losses through the base of the model, i.e., other than heat flux into the fluid flowpath. The new tip model incorporates an air gap region between a thin acrylic top piece and the bulk acrylic bottom section of the bucket. This air gap provides much better insulation against heat losses, and also allows the explicit measurement of these losses by thermocouples on the internal face. The new tip piece is removable and makes it easier to attach the thin-foil heating surface. The new tips were fabricated and received. Heaters for the tip geometries employing radiused edges are in the process of fabrication; delivery is scheduled for early in 2Q98. A test plan was approved by the GEPS bucket design team.

\section{Plans for Next Quarter}

The blade tip cascade will be used to obtain a more complete knowledge of the present tip geometries and the associated heat transfer and leakage, as well as to test alternate geometries and effects of deteriorated surface conditions. The inlet turbulence intensity will be measured again for confirmation of previous results, and some attempt may be made to increase this intensity. Heat transfer will be determined for at least one alternate rub-strip geometry, as well as for one reduced tip clearance gap case. The effect of tip rubs on heat transfer and leakage will also be determined.

\section{Technology Application}

The results from the testing performed under this task will be used directly in the design of the first- and second-stage bucket tips to improve tip performance and provide more accurate assessments of tip life. Tip geometries shown to have lower heat loads or less gap leakage, or both, will be incorporated into the design process.

\section{Section 2.2.2.4.6 (GTETEH) S1B External Heat Transfer}

\section{Objective}

The ATS turbine first-stage bucket is highly loaded both aerodynamically and thermally. It is crucial that the external heat loading for this component be predicted accurately. A nonconservative design heat load may result in a low life part design, while a too conservative heat load will lead to overutilization of steam coolant. As the heat load distribution is a major contributor to the bucket cooling design and its effectiveness, an accurate determination of the external heat transfer distribution is required to minimize the impact of other variable factors in the design. 
This task will provide external heat transfer coefficient distributions for the pitch section of the ATS turbine first-stage bucket. Cascade slave hardware will be manufactured by CRD for installation into the Transonic Blade Cascade facility at NASA Lewis Research Center, Cleveland. NASA will perform flow and heat transfer tests with a smooth airfoil and report heat transfer distributions at the design Reynolds number. Rough surface testing is optional in this program. This task is being carried out in conjunction with CRD's Research Alliance with NASA Lewis (no funds are exchanged in this Alliance).

\section{Progress for this Quarter}

Machining of the slave airfoils was restarted.

\section{Plans for Next Quarter}

Cascade slave hardware will be completed and shipped to NASA for test installation. The initial tests will consist of airfoil pressure distribution measurements.

\section{Technology Application}

The results of this task will be used to verify or alter the predicted design external heat loading for the first-stage bucket. Where the experimental results deviate significantly from the design predictions, changes in the blade coolant flow can be made to achieve a more efficient design.

\section{Section 2.2.2.5 (GTFFTS) Turbine Stator Design}

\section{Objective}

The inner and outer turbine shells will be designed, including a turbine stator cooling system to provide rotor/stator clearance control. A closed circuit coolant delivery and return system for the turbine flowpath stator components will be designed. Component, sub-assembly, and assembly flow tests will be incorporated concurrently. Implications for handling equipment (crane and manipulators) will be included in design considerations.

Steam-cooled turbine nozzles will be designed. Thermomechanical transient and steady-state analyses will be run to determine parts lives. Material, manufacturing, and heat transfer database expansion is planned and will be integrated concurrently.

Shrouds will be designed. Sealing systems will be selected for minimum leakage. Thermal and structural analyses of equiaxed or anisotropic materials will be applied as appropriate.

Calculations will be made of all flow in the cooling systems, including leakage flows, to support performance, thrust balance, and component temperature calculations.

Design of hot gas path seals will be based on laboratory tests. Seals developed for transitionpiece-to-nozzle-segment and intersegment interfaces will be evaluated in cascade tests. Both sealing and wear performance will be assessed. Manufacturing drawings and specifications will be produced.

\section{Progress for this Quarter}

The aerodynamic shape of the third-stage nozzle was generated and an electronic 3D solid model of the airfoil was constructed. Preliminary 2D analysis of the airfoil was completed. A 
3D electronic model of the fourth-stage nozzle was also constructed. Additional component definition was added to the turbine cross section, and preliminary interfaces between the individual components were established. 2D axisymmetric analyses were performed to define the layout/configuration of the inner and outer shells. Further shroud cooling studies were performed and the material and count for the third- and fourth-stage shrouds were defined. Secondary flow studies were performed to identify interstage compressor bleed to supply turbine cavity pressurization.

\section{Plans for Next Quarter}

3D electronic models of the $7 \mathrm{H}$ first- and second-stage nozzles will be constructed. The turbine cross section will be developed to enable critical interfaces to be frozen. A 3D finite element model of the third-stage nozzle will be constructed to enable a thermal and mechanical analysis to be performed to determine component life. 3D analysis of the turbine shrouds will also be performed. Further cooling trade studies and 3D stress analysis will be performed on the first- and second-stage shrouds to optimize the shroud cooling and sealing configuration. The shroud materials will be selected. Design work will begin on the first-stage piping system. Further secondary flow studies will be performed.

Detail design of the $9 \mathrm{H}$ production components will continue with further transient analysis and design modifications for enhanced producibility.

\section{Technology Application}

The turbine stator analysis and design effort defined the basis for the $7 \mathrm{H}$ and $9 \mathrm{H}$ production hardware.

\section{Section 2.2.2.6 (GTFFST) Structures Design}

\section{Objective}

The objective of this task is to design the exhaust frame and diffusers, steam gland, and aft bearing housing. Instrumentation and test plans for component model, factory, and field testing will be prepared.

\section{Progress for this Quarter \\ Exhaust Frame and Diffuser}

The $9 \mathrm{H}$ gas turbine, including exhaust structures and stator tube as well as test instrumentation, completed all assembly operations in the GE Greenville, SC, facility. It is now being prepared for FSNL tests in May 1998.

The aft diffuser duct completed performance tests and showed promising results (for minimal loss on pressure recovery) at CRD. Additional design analysis removed an acoustic resonance detected at low power (high turbine exit swirl angle). The speaker tests concluded that an acoustic mode shape at $\sim 3700 \mathrm{~Hz}$ exists and correlates with the flow acoustic tone seen in previous tests. However, the forcing mechanism for excitation does not appear to be flow driven since it does not vary with Mach number. Because the acoustic root cause is not identifiable using current test results, additional tests at operational conditions are planned. 
The exhaust frame flow test was held in the GE Greenville, SC, facility. A Design of Experiments approach was taken and detail flow and leakage modeling was completed.

$7 \mathrm{H}$ engineering sketches were sent to potential vendors for initial budgetary cost and cycle quotes. A lessons-learned meeting was held with the $9 \mathrm{H}$ vendor for design improvement ideas for the $7 \mathrm{H}$.

\section{Steam Gland}

The steam gland completed hydrostatic testing and was shipped to the GE Greenville, SC, facility. Plans to install gaskets around several aft-end bolts are in place for FSFL preshipment test to provide an acceptable pressure margin. The steam gland was installed in the gas turbine for FSNL testing.

$7 \mathrm{H}$ activity for a steam gland concept and preliminary design is progressing with the introduction of shorter, lower leakage seals (by using brush seal technology). Initial design revisions were proposed to the casting and machining vendors for producibility comments and cost quotes.

\section{\#2 Bearing Housing}

Transient thermal (machine trip) and flow analysis work is continuing on the heat rejection at the bearing that results from steam supply through the rotor bore and on obtaining acceptable deflections during off-design conditions. A detailed deflection and thermal analysis of the bearing seals and journal surface for steady-state and normal shutdown conditions was completed. Final gas turbine assembly, including standard bearing instrumentation for radial rotor vibration, bearing pad thermocouples, and stator vibration sensors, was completed.

\section{Plans for Next Quarter}

The exhaust structures and associated instrumentation are planned for FSNL testing in May 1998. The steam gland will be released. Purchasing of brush seals for application at one location in the initial $9 \mathrm{H}$ product unit will begin.

The $7 \mathrm{H}$ design activity will increase substantially with the planned advance material release for the exhaust frame. Design concepts will be frozen and structural preliminary design for initial releases of the frame will be completed. Initial design layout for the $7 \mathrm{H}$ steam gland and $\# 2$ bearing housing will be completed in order to freeze the $7 \mathrm{H}$ cross section.

\section{Technology Application}

This analysis and design effort establishes the basis for the $7 \mathrm{H}$ and $9 \mathrm{H}$ structure designs.

\section{Section 2.2.2.7 (GTFFMS) Mechanical System Design}

\section{Objective}

The objective of this task is to perform system level studies to optimize cost and performance. Performance, cost, weight, and other system level integration issues will be monitored and tracked. A flange-to-flange cross-section drawing will be maintained, and all mechanical interfaces will be controlled. All gas turbine systems, as well as the technical requirements for accessories, will be defined and specified. 


\section{Progress for this Quarter}

The focus of work was on completion of $9 \mathrm{H}$ detail design and first unit assembly, and $7 \mathrm{H}$ conceptual design. 9H first unit assembly was completed and the unit was shipped to Test Operations to begin test preparations. Supporting technology development that benefits both the $9 \mathrm{H}$ and $7 \mathrm{H}$ turbines is ongoing. Engineering milestone and manufacturing/assembly schedules were updated, reflecting the current cycles and customer requirements.

$7 \mathrm{H}$ system level studies continued to be performed to optimize cost, performance, weight, size, maintainability, reliability, and manufacturability. Optimization was limited only by schedule as decisions were made to support the $7 \mathrm{H}$ first unit assembly. Performance, cost, weight, and other system level and integration issues are being monitored and tracked. The systems review team, which includes engineering, manufacturing, sourcing, and maintainability personnel, continues to meet to review the merit of system issues and determine whether incorporation of ideas meets system goals.

The $7 \mathrm{H}$ Integrated Schedule was released, reflecting customer commitments and the cycles required to achieve success.

The maintainability, reliability, and serviceability team continues to work to ensure that all of the lessons learned for field operation are being incorporated into the $9 \mathrm{H} / 7 \mathrm{H}$ design. Reliability, availability, and maintainability (RAM) and failure modes effects analysis (FMEA) studies were completed, and goals were established for the $\mathrm{H}$ machines consistent with the Product Specifications.

Reviews for the current 9H New Product Introduction (NPI) tollgates were completed. Test and safety reviews of the $9 \mathrm{H}$ test plan-integrated with test stand assembly reviews at the GE Greenville, SC, facility - were conducted to ensure readiness for FSNL testing.

\section{Plans for Next Quarter}

The $7 \mathrm{H}$ Conceptual Design NPI process tollgate, with a GE Vice Presidential level review, will be completed. 9H FSNL testing will be completed. The 7H design to cost (DTC) and performance models will be updated to include the latest configurations. A meeting of the Utility Advisory Board (UAB) will be held to update the U.S. utilities on the progress of the GE $\mathrm{H}$ gas turbine. The cross-section drawings will be updated for the $7 \mathrm{H}$, reflecting conceptual design configuration and interface decisions.

\section{Technology Application}

The cross-functional systems review team will ensure that field experience lessons learned are incorporated into the component designs, thus optimizing performance, cost, weight, size, maintainability, reliability, and manufacturability.

\section{Section 2.2.2.7.1 (GTFFMS) Transient Gas Turbine Cycle Model}

\section{Objective}

The objective of this task is to create a more detailed transient model of the flange-to-flange ATS gas turbine for use in the overall plant transient simulation. The plant simulation in turn is used to define the gas turbine internal boundary conditions for parts design and analysis and 
overall plant control strategies. A real time simulation is used to test the actual control for the ATS gas turbine.

\section{Progress for this Quarter}

The transient gas turbine cycle model (without the heat soak, clearance, and stress model) was completed and checked out within the overall combined cycle plant transient model. Startup, shutdown, and load change transients were demonstrated. Transient switching of cooling media from steam to air and air to steam was also demonstrated.

Fast-calculating gas properties were developed and included in the model; faster-calculating steam properties were also included. By itself, the gas turbine model performs its calculations in real time, but the model will need further simplification to be used in the overall real time plant simulation required by the controls design group. The current model meets the speed requirements of the steam/gas process group for simulating the overall plant.

A major review with senior management was held in mid-February and the progress to-date reported. The reviewers suggested modifications to the heat soak, clearance, and stress model. They also suggested that input on modeling be solicited from the mechanical designers. The heat soak model was revised and re-programmed to implement the suggestions. Much effort was expended on extracting data from a detailed ANSYS rotor thermal transient run in the form required by the heat soak model. Mechanical designers are preparing data for the buckets, nozzles, and shrouds.

\section{Plans for Next Quarter}

Program checkout and debugging of the heat soak model will be completed in $2 Q 98$. Comparison of the heat soak model to more detailed analyses will be completed, and the model will be integrated into the ATS gas turbine transient model. Work on the stress model and clearance will be initiated in 2Q98 and completed at the beginning of 3 Q98.

\section{Technology Application}

The plant transient model is used in the design of the ATS gas turbine control system as well as the overall plant control and equipment. Simulation results of contemplated equipment configurations and control strategies define the operating environment and design condition of the ATS gas turbine.

The safe and reliable operation of the ATS gas turbine is critically dependent on off-base systems whose actions do not necessarily follow or result from operation of the gas turbine. For instance, the pressure and temperature of the cooling steam supplied to the ATS gas turbine must be maintained within an allowable band to preserve hot parts life. These issues and many others, such as FMEA, are studied through use of the transient plant model.

The steam/gas process group combined cycle plant transient simulation requires a model that has good fidelity with the steady-state ATS gas turbine cycle model and a reasonable computer execution time. The combined cycle model is used to define overall plant control strategies and design conditions for plant and balance of plant equipment. The simulated operation of the ATS gas turbine and its control within the overall plant then provides 
information on transient design conditions for the design of the gas turbine itself. The current transient model runs on a PC with the OS2 operating system using the PC-Trax program.

The controls design group requires a real time ATS gas turbine transient cycle model with an accuracy of $\pm 1 \%$ of the steady-state cycle model. The requirement for a real time transient model is due to the need to connect the computer model input/output electronically to the ATS gas turbine control for design and checkout. The real time requirement means that the model calculation time must be less than the sampling time of the actual control.

\section{Section 2.2.2.8 (GTFFPP) On-Base and External Piping Design}

\section{Objective}

The objective of this task is to design piping for fuel, air, steam, water, and oil transfer. A turbine base will also be designed for securing the ATS gas turbine to the foundation.

\section{Progress for this Quarter}

All on-base piping, turbine base, and electrical documentation required for the first FSNL test was completed, including the Cooling and Sealing Air piping system. All hardware required to support this test was ordered.

A hardware trial fit-up is planned in two phases prior to going to test. Phase 1, which is underway, is to trial fit-up all piping manifolds in their support structure, independent of the gas turbine hardware, in parallel with completion of the $9 \mathrm{H}$ gas turbine. Phase 2 will fit-up the entire on-base piping hardware on the gas turbine. These two activities are designed to minimize the risk of problems at the test stand by verifying the design via actual assembly prior to going to test.

Upon completion of this FSNL test, the data collected will be fed back into the on-base designs. These data will be used to improve those first FSNL designs as well as to complete the balance of non-FSNL tested systems such as Liquid Fuel, Atomizing Air, and Purge.

\section{Plans for Next Quarter.}

Phase 1 and Phase 2 piping fit-up will be completed. In addition, FSNL testing will be supported.

\section{Technology Application}

The turbine base and piping designs require the consideration of new ideas in this technology application. The turbine base must be capable of handling and transferring much larger loads than in previous gas turbine designs. This requirement is complicated by the limited space available to the turbine base because of the machine shipping envelope, the increased number of systems requiring piping for fluid transport, the piping size and quantity, and the foundation interface limits. In summary, the piping design challenge is driven by the increase in size and quantity of fluid systems support required by the turbine and the limited space around it. 


\section{Section 2.2.2.9 (GTFFIT) Instrumentation and Test}

\section{Objective}

The objective of this task is to instrument and conduct field tests that validate the ATS gas turbine design for mechanical integrity and operating performance of the unit and establish emissions performance. Test plans will be formulated and instrumentation will be specified. Compressor and turbine rotor telemetry systems will be developed and acquired.

\section{Progress for this Quarter}

The FSNL test plan and instrumentation Design Review was held on February 13, 1998. The FSNL test plan was revised to accommodate Design Review concerns and comments. The compressor instrumentation drawings were completed. The compressor blade strain gauges and wheel thermocouples were installed for selected stages.

In preparation for FSNL test, the design review was conducted in two phases. The first review was held on March 9, 1998, and the second on March 30, 31, and April 1, 1998.

The compressor and turbine assemblies were completed and the flange-to-flange gas turbine is in its final build phase for FSNL test.

\section{Plans for Next Quarter}

The gas turbine unit and power plant control, including skids, will be installed in the GE Greenville, SC, facility for FSNL test. The 9H FSNL test will be completed.

\section{Technology Application}

These are test plans to establish the instrumentation requirements for $7 \mathrm{H}$ and $9 \mathrm{H}$ FSNL and FSFL tests.

\section{Section 2.2.3 (GTET) Technology Validation}

\section{Objective}

The overall objective of this task is to provide confirmation of critical component design and technology. The validations include hot gas path component testing, sub-scale compressor testing, steam purity test trials, and rotational heat transfer testing. Technology enhancements that are not required for the first machine design but will be critical for future ATS advances in performance, reliability, and costs will be conducted.

\section{Section 2.2.3.1 (GTETNC) S1N Design}

\section{Section 2.2.3.2 (GTETRS) Rotor Steam Transfer}

\section{Objective}

For stable cooling of the turbine buckets, static flow tests will be conducted to validate the steam flows in the circuit to and from the buckets, through the rotor. These will establish flow losses for the unique components in the steam delivery circuit. 


\section{Progress for this Quarter}

The steam supply manifolds are used to distribute steam to the buckets. Due to the unique geometry of this component, pressure losses need to be measured to determine the effects on the supply of cooling steam to the buckets. A flow rig was used to test and characterize the flow losses in the manifolds and will be used to help validate the analytical models that will also model the rotational effects on the steam flows. These flow tests are nearing completion and the test data are being reduced for comparison to predictions. Initial observations of the flow distributions between buckets were observed to be flat, matching predictions.

\section{Plans for Next Quarter}

The supply steam manifold test will be completed and the test results compared with analytical results. Since the manifold design is now established, the rig will be modified to accept a return steam manifold model.

\section{Technology Application}

Rotor steam transfer tests are used to evaluate the design optimum for the $7 \mathrm{H}$ and $9 \mathrm{H}$ turbine bucket cooling.

\section{Section 2.2.3.3 (GTETSE) Rotor-Bucket Steam Transfer Spoolie}

\section{Objective}

Rotating air rig tests will be performed to validate the steam transfer spoolie design concept. (Spoolies are the hollow, spool-shaped ducts that bridge the gap between the steam delivery channels in the turbine rotor and cooling channels in the buckets.) A stationary steam test rig will be used for evaluation of durability and alignment effects on leakage.

\section{Progress for this Quarter}

Several tests of larger spoolies at simulated engine operating conditions of temperature, pressure, G-field, and environment (steam) were run on a wear and leakage test rig.

Preliminary testing in steam successfully demonstrated the spoolie wear rates, with the largest spoolies showing consistency with the previous, successful small spoolie results. Tests continued with an alternative coating specified for these latest tests. The rig was modified to cycle side loading in order to test fatigue as well as leakage endurance. Because of the delay caused by increasing the quality qualification requirements, test specimens are still being procured.

The durability of these seals depends in large part on the wear coatings applied. Although a preferred coating was selected from previous testing, many process parameters that affect seal performance can be varied. A test rig was set up to investigate wear, leakage, and durability in a steam environment, using coupons. A matrix of various process parameters was set up using Design of Experiments methods. The test samples were acquired. 


\section{Plans for Next Quarter}

A wear coating coupon test is currently planned to begin early in $2 Q 98$. This will help to establish the most desirable processing parameters for wear rate.

Further tests are planned for the spoolie steam wear/leakage rig, investigating alternate coating manufacturing parameters, in the pursuit of optimum wear and leakage. With the alternating side load, this testing will help verify low cycle fatigue predictions.

\section{Technology Application}

These tests will validate the rotor bucket steam transfer spoolie design.

\section{Section 2.2.3.4 (GTETRH) Rotational Heat Transfer}

\section{Section 2.2.3.4.1 (GTETRH) Rotational Effects on Bucket Mixing Ribs}

\section{Objective}

The addition of mixing ribs to turbine blade radial cooling passages was found to provide a more robust thermal design, without the severe reduction in performance measured previously, when evaluated in sub-scale models at low Reynolds numbers. Since this design improvement is scheduled for use in the ATS gas turbine, design data that incorporate this change need to be obtained at full-scale conditions in the operating range of interest.

A full-scale turbulated test passage of the appropriate aspect ratio will be constructed that will be identical to the one tested previously except for the addition of the new mixing rib geometry. This passage will be evaluated in the full-scale rotational test rig over the range of dimensionless parameters present in the ATS gas turbine.

\section{Progress for this Quarter}

The mixing ribs installed in the turbulated test duct in the full-scale test rig were evaluated over the buoyancy number range of interest at Reynolds numbers up to $1.3 \times 10^{5}$. The data taken to-date confirmed the benefit of using mixing ribs at high buoyancy numbers and also showed that the radial location of the ribs has a significant effect on the lead and trail side heat transfer. Additional small-scale tests were run to evaluate a range of mixing ribs configurations. A final report was written.

\section{Plans for Next Quarter}

This task was completed in 1Q98.

\section{Technology Application}

The new turbulator and rib design, which has to-date only been demonstrated in small-scale tests, is being employed to reduce the bucket cost and to yield a more robust design with improved performance at high Buoyancy numbers. This design will be validated by the fullscale data to be generated under this task. 
Section 2.2.3.4.3 (GTETRH) - Rotating Trailing Edge Heat Transfer Tests

\section{Objective}

As reported in Section 2.2.3.4.1, a number of tests were conducted to measure the heat transfer coefficients in the cooling passages of buckets. The completed tests focused on rectangular turbulated ducts (some with mixing ribs) of various aspect ratios representative of the range of geometries of cooling passages in most of the cooling circuit. The trailing edge cavities of the buckets, however, have a more triangular shape, and also have the difficult task of cooling the trailing edge. Validation of the ATS gas turbine second-stage bucket trailing edge passage is required primarily because of the strong effect of rotation on radial outflow, but also because of geometrical differences. The objective of the current task is to measure the heat transfer coefficients in a constant-area duct that captures all of these features. Tests will be performed in the full-scale rotational test rig.

\section{Progress for this Quarter}

Conceptual design reviews were held to set the test geometry. The second-stage bucket trailing edge passage was considered a more important test specimen than the first-stage bucket trailing edge passage, primarily because the second-stage bucket has radial outflow while the first-stage bucket has radial inflow. The duct cross section will be representative of the second-stage bucket passage cross section near the bucket root, since that is where the highest stresses are expected to occur. Geometrical features of this passage will be modeled.

A design team was assembled to perform the detail design of the payload, which is the new test piece that will contain the test duct. Most of the detailed drawings are complete, and construction was started on the duct itself. The payload is scheduled for completion by the end of $2 \mathrm{Q} 98$.

\section{Plans for Next Quarter}

In $2 \mathrm{Q} 98$, the focus will be on payload construction and instrumentation.

\section{Technology Application}

Results from these tests will be used to update cooling heat transfer boundary conditions for stress and life calculations for the second-stage bucket, and will also be used to reassess the heat transfer coefficients used in the first-stage bucket trailing edge cavity.

\section{Section 2.2.3.5 (GTETIH) Surface Enhanced Internal Heat Transfer}

\section{Section 2.2.3.5.2 (GTETLH) S2B Trailing Edge Heat Transfer Tests}

\section{Objective}

The task objective is to provide adequate experimental data to verify the performance of the second-stage bucket trailing edge cooling circuit. Because film cooling and trailing edge bleed cooling are incompatible with the ATS gas turbine objective of closed circuit cooling, the bucket trailing edge must be cooled completely by convection in the trailing edge cavity. The geometry and flow conditions in the trailing edge cavity are different from any analyzed and 
tested previously. The heat transfer coefficients in the cavity are determined experimentally using a scale model. The experimental results are used to guide and improve the design of the bucket.

\section{Progress for this Quarter}

No activity was carried out on this task in 1Q98.

\section{Plans for Next Quarter}

An experimental program will be initiated in order to address bucket trailing edge cooling requirements of the $7 \mathrm{H}$-specific design.

\section{Technology Application}

The results of the tests conducted as part of this task were used directly in the design of the second-stage bucket for the ATS gas turbine.

\section{Section 2.2.3.5.8 (GTETH) S1N Trailing Edge Heat Transfer Tests}

\section{Objective}

The first-stage nozzle trailing edge triangular cavity is air cooled and uses a combination of several cooling techniques. The turbulated main passage feeds several trailing edge slots whose heat transfer is enhanced by pin fins and high solidity turbulators. The flow and heat transfer inputs for the design are complex and need verification testing.

Specifically, the objective of the 1998 task is two-fold: to measure friction factors and heat transfer coefficient for the low-aspect-ratio/high-blockage trailing edge turbulated holes, and to support and verify a trailing edge region cooling design.

\section{Progress for this Quarter}

Trailing edge cavity heat transfer tests were initiated in an acrylic test section modified to form a 0.4-inch $\times 1$-inch flow passage. The first series of tests was conducted with a smooth tube. The heat transfer coefficients measured with the smooth tube are within $\pm 15 \%$ of the expected values. The second series of tests was conducted with turbulators. The testing covered Reynolds numbers ranging from 25,000 to 100,000 . The heat transfer coefficients measured show an enhancement value of 2.2 on average. The results are being analyzed in more detail and will be reported in $2 \mathrm{Q} 98$.

\section{Plans for Next Quarter}

Parametric variation of the turbulator height will be performed within the range agreed on with GEPS and results will be reported for future design selection. Tests will be performed to validate new cooling concepts.

\section{Technology Application}

The friction and heat transfer results obtained with the turbulated low aspect ratio passage will check the design tool predictions and form the basis for parametric evaluations. The testing of 
new concepts will verify the design assumptions with respect to the pressure drop and heat transfer coefficients.

\section{Section 2.2.3.5.11 (GTETTH) Production Airfoil Flow Checks \\ Objective}

The cooling flow circuits of the first- and second-stage nozzles and buckets of the ATS gas turbine have complicated flow configurations. Design flow models involve several empirical friction factors and flow element head loss coefficients that were taken from the best knowledge available. The models need experimental verification with typical cast components.

The objective of the flow checks, conducted with air, is to check the flowrates and static pressure distributions of typical cast first- and second-stage nozzle and bucket components. The results will be compared with the design flow model predictions. The measured overall coolant flowrates for a given overall inlet-to-exit pressure ratio will also form the basis for future quality flow tests to ensure that every component fulfills the flow design requirements.

\section{Progress for this Quarter}

Flow tests were completed with a cast second-stage bucket and four of the impingement inserts of the first-stage nozzle cooling circuits without and with inlet control orifices.

Tests were performed to verify the methods used in the design of the impingement inserts for the first-stage nozzle used in cooling cavities $1,2,3$, and 4 , and to measure the impingement jet supply pressure distributions along the jet supply flow areas. The first step was pin checking each jet hole diameter. Next, with all the impingement holes active, the overall flowrates were measured for three supply-to-discharge pressure ratios. The last step was measuring the static pressure distributions at the various impingement jet supply rows at selected locations along the impingement insert to check the uniformity of the supply pressure, which will be a measure of (1) the uniformity of the flow and (2) the impingement heat transfer distributions among the various rows of impingement jets. The flow tests for impingement inserts for cavities 3 and 4 were completed in 4Q97. The pin checks of the impingement holes and the flow tests for all the inserts and cavities $1,2,3$, and 4 were finished in 1Q98 without and with inlet metering orifices.

To provide a proper baseline comparison, the YFT model of the second-stage bucket was obtained and modified to reflect differences between the bucket in service and the bucket in the flow tests. Those modifications included using room-temperature air instead of steam; eliminating rotational effects; using low inlet pressures; and venting to atmospheric pressure. The YFT code was then run with these modified case files to provide a comparison with the measured data to come.

Several changes were proposed to the flow model to agree with the static pressure and flow measurements.

\section{Plans for Next Quarter}

The necessary flow tests and static pressure distribution measurements for the first-stage bucket and first- and second-stage nozzles and shroud cooling circuits will be performed. 


\section{Technology Application}

The flow and static pressure distributions results obtained with the cast components will check the design flow model predictions and ensure that the predictions are correct and that there are no regions that have friction and head loss factors different from the design assumptions.

\section{Section 2.2.3.7 (GTETCP) LCF Coupon Tests}

\section{Section 2.2.3.7.1 (GTETCP) LCF and Crack Propagation Rate Tests}

\section{Objective}

The E-beam high thermal gradient test facility will be used to test several nickel-based superalloy (N5) coupons for low cycle fatigue (LCF) durability. The coupons will be geometrically representative of a section of the turbine inlet nozzle airfoil containing hot and cold sides. Coupons will be instrumented for the evaluation of thermal conditions during testing. Tests will be performed to evaluate metal durability under conditions of temperature, thermal gradient, and stress representative of the ATS turbine inlet nozzle. Testing will be cyclic, developing cycles of exposure on the test coupons considered representative of engine cycles. Post-test evaluations of the TBC and metal conditions will be performed. Data will provide a basis for LCF life evaluations.

In addition to the high thermal gradient testing of superalloy coupons for LCF durability, this task will also assess the crack propagation rate of N5 in the presence of steam. This will be done in two ways: (1) isothermal, mechanically loaded testing of tubular specimens through which steam is passed and (2) high thermal gradient testing of a tophat specimen in the presence of steam. Post-test evaluations of the metal conditions will be performed. Data will provide a basis for LCF life

\section{Progress for this Quarter}

No additional testing was performed during $1 \mathrm{Q} 98$.

\section{Plans for Next Quarter}

A test plan will be completed after requirements for test conditions are identified. LCF tests of airfoil material will begin.

\section{Technology Application}

The results of the tests conducted as part of this task will be used as a basis for LCF life evaluation of the first-stage nozzle and first-stage bucket for the ATS gas turbine. 


\section{Section 2.2.3.8 (GTETSP) Steam Particulate Deposition}

\section{Section 2.2.3.8.1 (GTETSP) Steam Particulate Deposition Rig Testing}

\section{Objective}

The objective of this task is to measure the rate and location of steam particulate deposition in bucket tip turns and in two heat transfer structures to be employed within the ATS gas turbine nozzles and buckets. The information is to be translated into a steam purity specification and full-filter specification for the ATS gas turbine. The approach employed is to use gas turbine combined cycle (GTCC) steam flowing in series through a special filter specified for the ATS gas turbine, then through the tip turns in a specially constructed centrifugal deposition rig, and finally through two static specimens consisting of turbulated and impingement-cooled specimens. Amounts and locations of deposits in these specimens will be used to verify the predicted time-between-outages (TBO) results from ATS Phase 2 studies.

\section{Progress for this Quarter}

No additional testing or analysis was done in 1 Q98.

\section{Plans for Next Quarter}

A formal review will be held to discuss the results from the static specimen particulate deposition tests completed in 1997. Based on that review, a decision will be made regarding the need for additional testing.

\section{Technology Application}

The proper particulate filtering of steam used for bucket and nozzle cooling is critical to the reliable long-term operation of the ATS gas turbine. Data from tests under this steam particulate deposition task made it possible to establish the necessary steam filter specifications.

\section{Section 2.2.4 (GTMT) Materials Technologies}

\section{Section 2.2.4.1 (GTMTSE) Steam Effects on Mechanical Properties}

\section{Objective}

The objective of this task is to evaluate the candidate turbine materials for any effects due to operation in a steam environment. Tests of materials that are exposed to steam will be performed to measure fatigue crack propagation, LCF, and creep. Additional tests deemed necessary to meet design criteria will be performed. Comparisons will be made to data collected in air. Where necessary, the program will evaluate the roles of alternate heat treatments and/or surface treatments.

\section{Progress for this Quarter}

Dynamic crack growth rate testing in steam was concluded and a report was received from the test service provider. Additional creep testing of IN718 "Ingot 4" material in steam was 
initiated and reached 635 hours of test time. Work was initiated at a test service supplier to upgrade test fixtures to permit LCF testing between $800^{\circ} \mathrm{F}$ and $1100^{\circ} \mathrm{F}$. Crack propagation testing in steam with IN718 forged material focused on the threshold regime.

Machining of four LCF test specimens taken from cast IN718 elbow material was completed. The test specimens were submitted for testing at one temperature. Tensile testing on cast IN625 slabs was completed at three temperatures. Sub-size compact tension specimens were also machined from the cast IN625 and submitted for testing in steam.

Fifteen LCF samples, 16 crack growth rate samples, and 10 creep test samples of third-stage nozzle material test specimens were machined from cast slabs for mechanical tests in steam. First-stage airfoil material and second-stage bucket material cast slabs were obtained and machining of LCF specimens was initiated. Crack propagation testing in steam for the secondstage bucket and nozzle materials continued. Creep testing in steam for the second-stage bucket material also continued. The specimens logged over 700 hours of hang time.

\section{Plans for Next Quarter}

Dynamic crack growth rate threshold testing and steam LCF testing of IN718 "Ingot 4" material will be initiated. Machining of first-stage airfoil and second-stage LCF specimens will be completed. Mechanical property test programs will continue.

\section{Technology Application}

This task will evaluate the behavior of turbine materials in a steam environment in order to account for the introduction of steam cooling.

\section{Section 2.2.4.6 (GTMTCS) Compressor Structural Materials and Processes}

\section{Objective}

Mechanical and physical property tests will be performed on ATS compressor structural materials to provide an expanded mechanical and physical property database for design validation and enhancement. Material processing parameters for prototype manufacturing of the components will be selected based on design requirements and discussions with vendors. When necessary, material and processing specifications will be modified or new ones written.

\section{Progress for this Quarter}

The compressor discharge diffuser castings were produced. Supplier and Design Engineering meetings were held to resolve a number of production scale-up issues. Subsequent meetings were held in support of the development of an alternative design, alternative manufacturing processes, and new component supplier identification.

\section{Plans for Next Quarter}

Additional supplier meetings will be held as warranted. Evaluation of alternative methods of manufacture will continue. 


\section{Technology Application}

This task will continue characterization of compressor structural materials in test conditions that reflect service environments.

\section{Section 2.2.4.7 (GTMTRF) Turbine Rotor Forging Materials and Processes \\ Objective}

Processing parameters of forged large turbine rotor components will be optimized to achieve the desired forging attributes. These parameters include chemistry and processing temperatures as well as post-processing surface treatments. Sub-size and full-size forgings will be produced to verify and evaluate the processing approaches, and forging supplier process plans will be developed for all components. Forging acoustic properties will be determined by ultrasonic testing on test block and prototype parts. The attenuation, anisotropy, frequency bypass, and signal-to-noise ratio will be measured and used in fracture mechanics analyses to support rotor design. Optimized inspection methods, any necessary software, and scan plans will be developed based on the work with prototype parts. Property evaluations will be conducted to ensure that material behavior models used for design accurately reflect those achieved in parts made by the manufacturing process selected.

\section{Progress for this Quarter}

The second set of $\mathrm{IN} 718$ forgings started to arrive at the final ultrasonic inspection service supplier. Inspections were performed and results reviewed against established acceptance criteria. Work continued on developing a technique to correlate specific ultrasonic inspection results with specific microstructural features. Machining of specimens, metallographic examinations, and ultrasonic inspections were performed on the trepanned samples.

Smooth, bare LCF test specimens taken from IN718 "Ingot 4" were completed. The results were reviewed and will be published shortly. Creep testing of 12 "Ingot 3" specimens and 6 "Ingot 4" specimens was completed. The longest tests are approximately 18,000 hours for "Ingot 3" material and 7,800 hours for "Ingot 4" material. Tensile testing, crack growth rate testing, static and dynamic crack growth rate testing, and HCF testing continued.

\section{Plans for Next Quarter}

Exploration of the correlation of ultrasound results to features in the forgings will continue. Crack growth rate tests, creep rupture tests, LCF tests, and static and dynamic crack growth rate tests will continue. The Handbook curves will be updated, as appropriate, pending the results of these tests.

\section{Technology Application}

This task will enhance process capabilities for manufacture of turbine rotor forgings. 


\section{Section 2.2.4.8 (GTMTRS) Turbine Rotor Spoolies and Transfer Devices Materials}

and Processes

\section{Objective}

Although material selections for the cooling system delivery systems have been completed, this task will perform testing to verify properties and identify potentially better materials. Any applicable or needed coatings or joint materials will also be identified. Procedures for joining delivery components together and inspecting them will be evaluated.

\section{Progress for this Quarter}

The primary focus of Materials Engineering activity in 1Q98 was the support of component suppliers as they work the production scale-up issues in the manufacture of these parts. Visits were made to the manifold, elbow, and bore tube suppliers to confirm the validity of process development work. Project plans were revised to reflect the need to address issues as these processes were developed.

The electron-beam welding process for the manifolds was dropped in favor of a manual gas tungsten arc weld (GTAW) process. A new supplier was identified for the GTAW process, and samples of test specimens were obtained for metallographic evaluation. Development work of a flux GTAW continued at the Edison Welding Institute. Process specifications were drafted and/or revised to reflect input from the process trials. A shot peen supplier was qualified in Ohio and will be used to process various steam delivery components.

The sliding wear rig was re-assembled and stiffened for block-on-shoe wear testing. Shakedown testing of the rig was completed, and a baseline coefficient of friction was established for bare $\mathrm{IN} 718$ at room temperature. A designed experiment was developed to determine the effect of application method, level of coating oxidation, and heat treatment. Additional test samples were received. Fabrication of specimens for determining the elasticplastic and thermal properties of the coating was initiated. Fabrication of specimens for determining the coefficient of thermal expansion of the coating was also initiated.

\section{Plans for Next Quarter}

Welding procedure development will continue at the suppliers' sites. Test results collected on first piece qualification (FPQ) samples will be evaluated to complete supplier qualifications. Wear testing of coatings produced by various processes to down-select the coating with the best wear properties will continue. An additional surface treatment of $\mathbb{1 N} 718$ will be selected for future testing. Testing of mechanical properties of the coating will begin.

\section{Technology Application}

This task will develop processes and mechanical property data to optimize steam delivery hardware manufacture and subsequent operation. 


\section{Section 2.2.4.9 (GTMTSB) Structural Bolting}

\section{Objective}

Mechanical and physical property tests on two high-strength bolting materials will be conducted at ATS turbine conditions. If required, manufacturing trials will be conducted to optimize forming processes.

\section{Progress for this Quarter}

Stress relaxation tests on two different bolting materials were terminated. Data were reviewed for publication.

\section{Plans for Next Quarter}

Results will be communicated to Design Engineering.

\section{Technology Application}

This task will increase the database for flange/flange and wheel/wheel bolting applications.

\section{Section 2.2.4.10 (GTMTTA) Turbine Airfoils Materials and Processes}

\section{Objective}

Microstructure and mechanical properties will be evaluated for full-sized castings processed in this program. A comprehensive program will yield final specifications with appropriate heat treatments and will quantify the effects of ATS airfoil geometry and structure/property variability. Casting processes will be developed for all airfoils by employing developmental casting trials. Critical nozzle and bucket long-term material properties will be measured at elevated temperatures. Metallic coating systems will be developed for internal and external oxidation protection of the airfoils. Samples will be coated using various techniques for optimization studies and process verification.

\section{Progress for this Quarter}

Additional test specimens were machined from slabs of the third-stage nozzle material. Additional first-stage airfoil LCF specimens were manufactured by milling. LCF and HCF testing on second-stage bucket material castings with intentionally placed internal defects was completed. Review of the test results was initiated. Additional design curves were issued for the first-stage airfoil material, the third-stage nozzle material, and the second-stage bucket material, including Goodman diagrams at two temperatures, LCF data at various temperatures, and creep data.

\section{Plans for Next Quarter}

Coating of third-stage nozzle material test specimens will be completed. LCF testing on milled first-stage airfoil material specimens will be initiated and completed. Post-test specimen analyses on defect-containing second-stage material LCF test specimens will be completed. 


\section{Technology Application}

This task will enhance the database of mechanical properties at service conditions for bucket, nozzle, and shroud materials.

\section{Section 2.2.4.11 (GTMTCB) Combustion Materials and Processes}

\section{Objective}

Properties of materials for combustion components will be evaluated at ATS conditions.

\section{Progress for this Quarter}

Baseline tensile testing of the sheet material was completed. Initial baseline LCF testing was completed. Creep specimens were machined. Welded LCF blanks were prepared and inspected and will be sent out for machining. Welded creep and tensile specimens continue to be tested. A cast transition piece was made to complete a designed experiment. Review of the experimental results was initiated.

\section{Plans for Next Quarter}

Creep testing and testing of welded specimens will start. Testing of LCF specimens will be completed. Welding of creep and tensile specimens will be completed. Progress to-date will be reported. Analysis of the casting experiment will conclude. Base metal LCF and tensile testing will be completed. Machining and testing of creep specimens will be initiated. The welded test specimens will be finished and testing will begin. All results will be reported to Design Engineering.

\section{Technology Application}

This task will enhance processes and mechanical property data to optimize combustion hardware manufacture and subsequent operation.

\section{Section 2.2.4.15 (GTMTAR) Airfoil Repair}

\section{Objective}

Existing techniques will be evaluated and adapted for the material/geometry combinations unique to the ATS turbine airfoils to extend component life.

\section{Progress for this Quarter}

Refinement of braze and weld repair processes for first-stage airfoil material continued. Repair development was initiated for the second set of hardware. Additional laboratory-produced brazes and welds were evaluated and screened based upon results of limited mechanical property tests.

\section{Plans for Next Quarter}

Studies will continue to evaluate and enhance repair methods for hot gas path materials with selection of process and subsequent optimization of parameters. 


\section{Technology Application}

The ability to repair airfoils will result in more cost-effective flowpath components.

\section{Section 2.2.5 (GTTT) Thermal Barrier Coating Technology}

\section{Section 2.2.5.1 (GTTTSD) Coating System Development}

\section{Objective}

Plasma spray thermal barrier coating (TBC) coating processes will be developed for specific ATS combustion and turbine components. Both axisymmetric and non-axisymmetric plasma gun and part motions will be developed. Coating evaluations will consist of metallography, property measurements, and thermal cycling exposure. Computer simulations, motion trials on part replicas, and spray trials on parts will be used for improving robot path planning accuracy. Improved process monitoring will be developed to increase process repeatability and control.

The TBC manufacturing technologies portion of the task will focus on integration and compatibility between TBC processing and other component manufacturing steps. Techniques to prepare components for spraying will be defined. Fixturing and masking will be developed. Surface finishing techniques will be developed.

The TBC process and diagnostics portion of the task will focus on achieving a better fundamental understanding of the TBC application process. Specific process conditions critical to the thickness and properties of the TBC system will be evaluated. Continuing work will focus on identifying critical-to-process characteristics (CTPs) for the ceramic top coat and metallic bond coat. The CTPs will be those directly controllable aspects of the coating process that most strongly influence process variability and TBC quality.

The TBC nondestructive evaluation (NDE) portion of the task will develop NDE techniques to measure attributes and properties of TBCs on turbine hardware that are relevant to manufacturing. The primary focus will be on development of methods to measure coating thickness. A secondary focus will be on development of methods to evaluate coating microstructure

\section{Progress for this Quarter}

\section{Robotic Motion Control and Programming Methods for Airfoils}

The three FANUC Robotics M710i/RJ2 systems (two development systems located in Schenectady, NY; one production system located in Greenville, SC) were configured to ensure matched performance. The RJ2 Controller was upgraded to accept 4 times larger robot programs, translate programs 8 times faster, and transfer files 20 times faster. These improvements were needed because the motion programs for the ATS airfoils have increased considerably in size to improve control of TBC thickness and microstructure. A Visible Laser Measurement System was developed for use by the robot operator during motion verification. Measurement accuracy was improved by 50 times by using a higher resolution laser, and a simpler user interface was installed. 
Both nozzles and buckets require simultaneous movement of the spray tool and part motion to properly access all part surfaces and satisfy the process requirements for surface velocity, standoff distance, and spray angle. Four methods for robotic motion control and programming were developed and tested. Two approaches were forms of Tool Center Point (TCP) motion control that require stationary targets in order to define motion along the 3D part surface. These approaches were inadequate because of the geometric complexity of the ATS hardware. The other two methods were forms of inverse time motion programming, which allow simultaneous movement of the spray tool and part motion. The first is a FANUC Robotics product called Segment Time Programming (STP), which utilizes the built-in path planning capabilities of the RJ2 controller. The second is a custom form of Inverse Time (IT) developed for GE by FANUC Robotics. Both STP and IT demonstrated motion control performance within the requirements for the ATS program. Initial motion programming approaches for nozzles and buckets were selected. Designed experiments are being used to optimize motion programming for various parts.

Two off-line robotic motion simulation systems were developed and tested. The first is a Tecnomatix product called $\mathrm{ROBCAD}$, which supports full $3 \mathrm{D}$ modeling of robotics motion with capabilities for detecting motion limits (position and velocity) and collisions. The ROBCAD/STP programming tools are in place, and motion development for ATS hardware is underway. Planned ROBCAD enhancements will further improve functionality and reduce the amount of time required to perform collision detection. The second simulation tool is a CRD product called Coordination through Short Motion Programming (CSMP). CSMP takes into account the robotic system capabilities for motion position, velocity, and acceleration based on equipment characterization studies performed at CRD. Version 1.0 of the ROBCAD Advisor software program was provided to GEPS.

A decision was made to develop an off-line simulation tool to predict TBC thickness on ATS airfoils. This will be accomplished by modifying a tool used to predict the thickness of metallic overlay coatings applied by vacuum plasma spray (VPS; two degrees of freedom). The new tool is needed to reduce the cycle for developing robot motions for TBC (seven degrees of freedom), improve powder efficiency, and achieve more uniform TBC thickness distributions.

\section{Nozzle Coating Trials}

Production ATS first- and second-stage nozzle castings were received for coating trials. The ATS nozzle replica was used for two sets of designed experiments, beginning with constant velocity tests and leading to a series of variable velocity tests. Motions were developed using ROBCAD/STP programming. The constant velocity trials are complete and the motion performance was within specifications and very repeatable.

\section{Bucket Coating Trials}

Two sets of spray trials using the ATS bucket replica were completed. The TBC top coat thickness measurements from the first set of replicas were used to improve the thickness model. The improved model was able to explain $80 \%$ of the variation seen in the top coat thickness measurement and was used to develop a modified spray motion for the bucket replica. This motion was used to spray the second set of replicas and reduced the measured variation in top coat thickness by $24 \%$. 
Constant velocity trials gave motion performance that was slightly outside the specification limits, and TBC thickness control was not acceptable due to bucket geometric effects. These geometric effects can be compensated for by using variable velocities; however, variable velocity trials showed that motion performance was significantly outside of the specification limits. These motions were developed using ROBCAD/STP programming, and the performance shortfalls are attributed to the fact that buckets have much shorter velocity zones than the nozzles, as a result of their smaller sizes and more complex shapes, which require more aggressive motion accelerations. The CSMP Path Planning System addresses these shortfalls, and initial trials using the ATS bucket replica were very encouraging.

\section{Shroud Coating Trials}

A series of six spray runs was conducted on an ATS shroud replica to assess the coating microstructure and thickness on the edges and flowpath of the part. Metallographic and thickness evaluations are underway and preliminary analysis showed that two of the motions produced acceptable coating. Additional iterations are needed to refine the selected spray motion.

\section{TBC Process Development for Transition Pieces}

Note: Funding for this development is being conducted under an internal program. Reporting will continue to provide continuity between the ATS and non-ATS work scopes.

Two coating processes were selected for evaluation as cost-saving alternatives to the advanced coating process currently under development. Coating properties will be measured as a function of exposure time in a furnace cycle test (FCT) to develop predictions for coating life under service conditions. Furnace cycle testing of both candidate processes was completed and mechanical property testing is in progress.

A set of FCT specimens tested in 1997, which failed by oxidation and detachment of the bond coat, was analyzed to provide an estimate of bond coat life under service conditions. It was found that the current bond coat system will provide sufficient protection to the substrate material to exceed base requirements. This analysis is being supplemented with extended-time exposures ( $>1,000$ hours at operating temperatures) to allow more accurate extrapolation of the prediction model.

\section{Bond Coat Process Development}

Note: Funding for this development is being conducted under an internal program. Reporting will continue to provide continuity between the ATS and non-ATS work scopes.

Testing and evaluation of protective bond coats on substrate materials to be used for first- and second-stage airfoils, shrouds, and transition pieces continued with additional furnace cycling and oxidation rig hours accumulated. A selection of bond coats for the first ATS hardware was completed, and specifications were written for the materials and techniques chosen. The focus in 1998 is the development of a new bond coat chemistry that is expected to meet all ATS requirements.

\section{Development of Coatings for CMAS Mitigation}

Note: Funding for this development is being conducted under an internal program. Reporting will continue to provide continuity between the ATS and non-ATS work scopes. 
TBC protective coatings will be developed to extend turbine service conditions beyond those currently allowable by improving resistance to deposits of calcium-magnesium-aluminumsilicate (CMAS). Activities in 1998 will focus on processing of candidate coating compositions by chemical vapor deposition (CVD).

\section{TBC Manufacturing Technologies}

Controlled TBC surface finishing methods are being developed to ensure both acceptable surface finish and uniform material removal over all regions of the airfoils, fillets, sidewalls (nozzles), and platforms (buckets). Conventional finishing techniques, such as tumbling and grit blasting, were not acceptable because the differences in removal rates at different locations (e.g., fillets and leading edges of airfoils) make it impossible to maintain a uniform coating thickness. Continued development is focusing on computer numeric control (CNC) machining operations such as grinding, belting, or milling.

A coated ATS second-stage nozzle was provided to the CNC machining vendor, and development of fixtures, grinding wheels, and machining motions is underway. because cost and process times of the $\mathrm{CNC}$ machining are significantly higher than for current production finishing, alternative processes will continue to be explored with appropriate cost/benefit and risk analyses performed. A technique that utilizes part-specific soft tooling and conformable abrasive media has shown good initial results and is being further evaluated. A combination of shot peening and hand finishing is used for current production. Gravity-assisted shot peening can be used for ATS buckets. Extension of this process to ATS nozzles will require robotcontrolled shot peening.

Several processes for applying bond coat and top coat to the welded joint of the second-stage nozzle doublets were evaluated. These nozzles are cast as singlets and welded into doublets following application of TBC to the nozzle airfoil and sidewall surfaces. Metallurgical evaluation showed that the weld process has minimal effect on the TBC structure. However, access to the weld joint is not adequate for the application of advanced TBC using the standard spray equipment. As a result, four approaches were investigated: (1) use of an air plasma mini-gun for top coat and, possibly, bond coat deposition, (2) use of a braze alloy for the bond coat, (3) use of a slurry-applied ceramic for the top coat, and (4) use of a highvelocity oxy-fuel (HVOF) bond coat process.

The prime focus for the first ATS nozzles is the HVOF bond coat process with the air plasma mini-gun for top coat. Longer-term approaches are using an air plasma sprayed (APS) bond coat that is post-densified with braze alloy, or brazing on a free-standing section of TBC (bond coat + top coat). Slurry-applied ceramic top coats were abandoned because of poor mechanical properties of the ceramic.

Techniques for applying TBC over strain gauges were evaluated. Trial plates were fabricated by applying a standard TBC bond coat and top coat followed by a heat treatment. The TBC was then locally removed by the gauge vendor for installation of the strain gauge. A ceramic overcoat was applied by the vendor to restore thermal protection in the gauge region.

Spray trials showed that unmasked cooling holes on ATS buckets and nozzles were reduced roughly $50 \%$ in diameter by application of TBC bond coat and top coat. Two techniques were 
evaluated for removal of the coating from the cooling hole. One of these techniques was down-selected for production and is being transitioned to a vendor.

TBC Process and Diagnostics:

Focused efforts in 1998 include: (A) Evaluation of alternative plasma guns; (B) Process variables that control as-sprayed TBC roughness; (C) Transfer of technology for TBC process sensors.

\section{(A) Evaluation of alternative plasma guns}

Plasma guns that operate at longer standoff distances and higher powder injection rates are desired for manufacturing. Experiments were performed to evaluate coatings sprayed using four different guns. Preliminary analysis of the data suggests at least one gun has the capability to achieve TBC properties similar to the present plasma gun at much longer standoff distances and up to 4 times higher powder injection rates.

Deposits were made using the current plasma gun to establish baseline data. Mechanical and metallurgical analyses of coatings made using two alternative guns were completed. One of the guns gave very good results Another gave poor results using conditions within the manufacturer's recommendations. Experiments were begun to determine the capability of this gun outside the manufacturer's limits. A third gun experienced significant reliability problems and will be evaluated as a longer-term effort.

(B) Process variables that control as-sprayed TBC roughness

Evaluations of process variables that control as-sprayed TBC roughness are being conducted to minimize the need for post-spray TBC surface finishing and/or to improve the effectiveness of low cost TBC finishing processes. The baseline finishing process is gravity-assisted shot peening (GASP) followed by hand polishing.

Samples were machined from plates having various degrees of TBC roughness. The samples were welded to a production bucket and put through a standard GASP cycle to assess the effect of as-sprayed roughness on roughness following GASP. A strong relationship between as-sprayed and as-GASPed roughness was observed. Surface roughness was measured on an additional 52 plates that were sprayed with TBC using various process conditions. Statistical analysis of these plates revealed several key process conditions that affect as-sprayed roughness.

(C) Transfer of technology for TBC process sensors

TBC process sensors that were evaluated by CRD earlier in the ATS program and in parallel programs were selected for transition to GEPS.

The infrared optical pyrometer data acquisition system was successfully tested during coating of an ATS second-stage nozzle. Specifications for the system were established.

Nondestructive TBC Thickness Measurement

An automated ceramic coating thickness measurement system using a flexible eddy current probe in combination with a multi-axis contact probe scanner was developed. Installed Coordinate Measuring Machines (CMMs) in Schenectady and Greenville are used as the scanning devices. The other elements of the system include redesigned eddy current probes, a 
redesigned probe holder, a Nortec 24 eddy current instrument, a Pentium computer, motion control software, and a modified version of the eddy current software being used for manual eddy current measurements. Two flexible eddy current probes of different configurations will be used initially to fully inspect ATS nozzles and buckets.

Coordinate measuring machine (CMM) motion programming and control are performed using a Tecnomatix software product called VALISYS. This software was installed and successfully tested with the automated inspection system in Schenectady; however, Tecnomatix had to significantly modify the Machine Tool Interface in order to perform inspections efficiently using this CMM. It is now possible to run through several hundred points without a data transmission interruption.

The first set of development fixtures was received. Implementation of automatic testing at the GE Greenville, SC, facility was begun. Software changes were made to transmit the eddy current thickness measurements into the manufacturing quality database. Final tests of this software are planned for 2Q98. A second thickness measurement system was assembled, tested, and shipped to the CNC machining vendor to support development of nozzle surface finishing. A new 6-axis CMM, which will offer three more degrees of freedom than the conventional 3-axis CMMs now installed, was purchased for installation in Schenectady later this year. The final machine design was reviewed and approved. The software specifications are in development.

A test matrix for determining the effect of variations in the ceramic coating and bond coat thicknesses on the measured ceramic coating thickness was planned. Additional thickness calibration specimens were constructed using the newly developed bond coats as well as the substrate alloys corresponding to the various ATS buckets and nozzles.

Nondestructive TBC Microstructure Evaluation:

Laser ultrasound will be used for nondestructive evaluation of TBC microstructures. The laser ultrasonic approach uses a Nd:YAG laser to produce a shaped source beam onto the target coated substrate, generating an ultrasonic Lamb wave that propagates in the coating. A laser interferometer senses the propagating wave signal, which is stored on a computer and analyzed for frequency dispersion content, i.e., ultrasonic velocity as a function of frequency.

Laser ultrasound elastic moduli were shown to correspond well with measured dynamic moduli of attached TBCs. A large matrix of samples-produced with various powders, gun conditions, and substrates-will be used to further verify and improve the analysis tools. A quality function deployment (QFD) to define the engineering and manufacturing requirements for the laser ultrasound system was completed.

\section{Plans for Next Quarter}

Robotics Motion Control and Part Coating Trials

ROBCAD/STP motion development based on constant and variable velocity trials on ATS hardware and replica shapes will continue.

Evaluation of CSMP in support of motion development for ATS hardware and replica shapes will continue. 
Spray motions for coating of shroud edges and flowpath will be improved.

TBC Manufacturing Technologies

CNC grinding trials will be conducted using an ATS second-stage nozzle. Robot-controlled shot peening for ATS nozzles will be investigated.

Process development for coating of the second-stage nozzle weld joint will continue. HVOF bond coats will be applied at various process parameters and subsequently coated with TBC by mini-gun. Mechanical properties and thermal cycling tests will be conducted. New brazed bond coat samples will be fabricated and tested.

\section{TBC Process and Diagnostics}

Baseline data for the current plasma gun will be completed. Evaluations of the first alternative plasma gun will continue. The second alternative gun will be evaluated at higher plasma power conditions.

The plasma spray process conditions that have the highest effect on as-sprayed TBC roughness will be identified.

Automated spreadsheet macros for efficient post-processing of IR imaging tapes will be developed.

Note: Experiments to evaluate APS repair of a new make TBC will be performed only if needed by manufacturing.

Nondestructive TBC Thickness Measurement

Metallographic measurements of bond coat thickness on specimens with eddy current measurements using the flexible probe system will be correlated. Compound curvature specimens, deferred from 1997 due to a delay at the supplier, will be built.

Installation of an upgraded manual thickness measurement system will be completed in Greenville. Installation of automated thickness measurement systems will continue in Greenville and at the CNC machining vendor.

Nondestructive TBC Evaluation:

An external review on moduli measurements will be conducted. Laser ultrasound data for expanded coating matrix will be acquired.

Lower cost laser ultrasound architecture will be evaluated.

A new laser ultrasound interferometer will be installed and checked out.

Fluorescent Penetrant Inspection capability for parts will be determined.

\section{Technology Application}

The process for applying APS TBC to ATS combustion and turbine components will be defined. This process will define the baseline upon which coating durability will be evaluated and evolutionary improvements will be made. 


\section{Section 2.2.5.2 (GTTTRR) TBC Risk Reduction}

\section{Objective}

TBC durability will be evaluated under conditions very similar to the surface temperature, thermal gradient, and stress state of TBCs in ATS applications. An E-beam rig capable of inducing high thermal gradients will be used to assess the relative durability of various TBCs, and the controlling mechanisms of TBC failure will be characterized. TBCs with a spectrum of microstructures will be tested to determine the role of TBC thickness on stress development and failure mode in high thermal gradient conditions, the failure modes of various TBCs of different microstructures and deposition techniques, the role of number of cycles and hold times at high temperature on TBC failure mode, and the role of bond coat composition and roughness on TBC life and failure mode. The effects of environmental contaminants on TBC performance in high thermal gradient conditions will be investigated. Numerical modeling will be used to determine the stress, strain, and thermal gradient conditions in the various TBCs during the tests.

\section{Progress for this Quarter \\ Electron-Beam High Thermal Gradient Tests}

Two TBC-coated tophats were furnace aged to $50 \%$ and $75 \%$ of expected ATS TBC life. These tophats were then tested under full ATS conditions for 100 hours and 2500 cycles. No spalls or hot spots were observed during testing.

TBC degradation during this testing is being evaluated by comparing the microstructure and compressive-shear failure strains between hot and cold regions of the tested tophats. No systematic difference in TBC horizontal cracking, bond coat oxide thickness, or TBC residual strain to failure was observed between the hot and cold sections of the tophats. In addition, no systematic difference in TBC residual strain to failure was measured between tophats with different pre-test furnace aging. It is possible that the compressive-shear test results are confounded by the effects of variations in single crystal substrate crystallographic alignment, which can induce significant measurement error. New laser ultrasound NDE techniques under development may allow future samples to be evaluated before and after testing without concern for the influence of crystallographic alignment.

The third CMAS tophat was tested under conditions that produced partial CMAS infiltration into the TBC. No TBC spallation occurred after 87 two-minute cycles, although melting and infiltration of CMAS was confirmed by destructive evaluation of this tophat. A duplicate tophat (CMAS \#4) was prepared and installed for testing. Only 18 low-temperature cycles could be performed on this sample before the rig was shut down for filament replacement.

The first fillet tophat was tested under full ATS conditions for 2500 cycles. The sample was designed to simulate the thermal and stress conditions in the TBC near-critical fillet region of the ATS first-stage nozzle. The TBC was machined to produce a uniform thickness in the fillet region. No spalls or hot spots were observed during the testing; however, the TBC top surface ran hotter and the metal ran colder than expected due to the increased thermal resistance of the coating in the fillet. The higher thermal resistance is caused by high porosity and poor splat-to-splat bonding, which are caused by geometric effects during the spray process. The thermal conductivity of the top coat and bond coat in the fillet will be measured 
on free-standing specimens prepared from the tophat. A second fillet tophat was prepared for testing.

\section{Cascade Nozzle Evaluations}

(A) Heat transfer test nozzles

TBC-coated nozzles used for cascade heat transfer evaluations were inspected visually and examined in metallographic cross section. In addition, the internal steam cooling impingement patterns were captured for inspection after nozzle sectioning by replicating the internal cooling surfaces with castable RTV silicone rubber.

Visual inspection revealed a significant TBC spall parallel to the airfoil chord on the suction side of nozzle \#30. Metallographic inspection revealed that the spallation in the TBC occurred at the layer thickness where additional TBC had been added on the suction side in a secondary application of TBC top coat. The coating microstructure at the interface between the primary and secondary TBC layers exhibited a distinct plane of weakness in the coating. The creation of the spall was found to coincide with the passage of a transient combustor hot streak. It seems likely that the spall resulted from the interaction of the transient thermal stresses and the weak layer in the coating.

(B) LCF test nozzles

A second set of cascade nozzles is currently under test to study LCF behavior. Spallation patterns similar to those observed in the heat transfer nozzles are beginning to develop. The LCF nozzles were coated using a robot program similar to that used for heat transfer nozzle \#30.

\section{Plans for Next Quarter}

\section{Electron-Beam High Thermal Gradient Tests}

Fillet TBC endurance samples will be tested at full ATS conditions until 100 hours and 2500 cycles have accumulated or a TBC hot spot is observed.

The fourth CMAS sample will be tested until 100 cycles or a TBC hot spot is observed.

The $13 \mu \mathrm{m}$ IR pyrometer for measurement of TBC surface temperature will be installed and testing will begin.

\section{Cascade Nozzle Evaluations}

Evaluation of the LCF cascade nozzles is to be performed pending an internal review of the results on nozzle \#30.

\section{Technology Application}

Durability of the baseline TBC in an environment simulating that of the ATS baseline will be evaluated. These results will establish confidence that the TBC will provide acceptable minimum durability for safe and reliable operation of the ATS turbine within the time frame of the first inspection interval. 


\section{Section 2.2.5.3 (GTTTDD) TBC Design Data and Life Analyses}

\section{Objective}

Thermomechanical failure modes in advanced TBCs will be identified, classified, and defined using empirical methods. Experiments will be performed to find key relationships among plasma spray processing variables, coating microstructure, coating physical and mechanical properties, and coating performance under simulated ATS conditions.

The relative contribution of oxidation and cyclic damage to the failure of two TBC systems will be evaluated in order to estimate the TBC life under the ATS gas turbine conditions. This will be accomplished by furnace cycle testing TBC systems using a series of dwell times per cycle $(0.1$ to 20 hours $/$ cycle $)$ and dwell temperatures $\left(1037^{\circ} \mathrm{C}-1148^{\circ} \mathrm{C}, 1900^{\circ} \mathrm{F}-2100^{\circ} \mathrm{F}\right)$, and incorporating the results into an existing cumulative damage model. Accelerated testing at temperatures below $1037^{\circ} \mathrm{C}\left(1900^{\circ} \mathrm{F}\right)$ will be accomplished using a tensile thermomechanical fatigue test that superimposes cyclic mechanical strain upon the cyclic thermal strain. In support of the modeling approach, microstructural features of the bond coat and ceramic top coat will be examined.

Numerical analyses will be performed to determine TBC stress states expected in ATS turbine components and in laboratory thermal cycling tests. The influence of the TBC stresses on TBC failure modes will be examined. Specially developed finite elements will be used for modeling the behavior of the interface cracks and free-edge stress singularities. The effects of bond coat roughness on TBC stress state, crack driving forces, and delamination failure will be examined. Parametric studies to determine the effects of bond coat and top coat properties on the TBC stress states will be performed.

The spatial and run-to-run variability of TBC thermal conductivity will be evaluated. Improved understanding of this variability is essential because the variation in TBC thermal conductivity can be several times greater than that seen in metals as a result of variations in TBC microstructure, and can therefore lead to design inaccuracy. Various methods of measuring thermal diffusivity and conductivity on flat and curved samples will be evaluated. The gas pressure dependence of thermal conductivity as a function of temperature will be measured. The results will be used to estimate the thermal conductivity of TBC at ATS conditions. The effect of thermal aging on TBC thermal conductivity will be quantified.

\section{Progress for this Quarter}

\section{Furnace Cycle Test}

Furnace cycle testing at $1037^{\circ} \mathrm{C}\left(1900^{\circ} \mathrm{F}\right)$ was started for two $\mathrm{TBC}$ systems, using dwell times of $0.1,0.75$, and 10 hours per cycle. These furnace cycle tests are projected to continue throughout 1998, although some specimens will be removed at planned intervals for examination. In order to identify the variation in TBC life resulting from small variations in processing, samples were batched according to spray run number, and randomized within batches.

\section{Thermomechanical Fatigue Testing}

A detailed test plan was developed to quantify the life and properties of various TBC systems needed on ATS parts. A total of 13 TBC-substrate systems were selected and prioritized for 
testing in 1998 and 1999. The relative contributions of time-dependent (oxidation) damage and cycle-dependent (fatigue) damage to ultimate failure of the TBC will be evaluated through mechanical tests and metallurgical evaluations. Mechanical tests include thermomechanical fatigue, compression shear, tensile, ballistic impact, and hardness tests. Thermomechanical fatigue (TMF) data will be used with furnace cycle test (FCT) data to predict or estimate TBC life. Other data will be used to rank the TBC based on empirical parameters.

Raw materials necessary for specimen fabrication were procured. Test rigs and specimen fabrication resources were identified. TMF specimen geometry was established through vendor trials.

\section{Thermal Conductivity}

Aging studies will continue to provide improved design data for TBC thermal conductivity as functions of temperature and aging time.

A new thermal diffusivity measurement apparatus was installed at CRD. In the past, measurements of thermal diffusivity were performed at Oak Ridge National Laboratory. Samples used for the aging study (measured last year at ORNL) were measured again at CRD using the new equipment. Thermal diffusivity values were identical within the range of experimental uncertainty. $\mathbb{R}$ detector non-linearity was evaluated and shown to be negligible for the range of temperatures used for current studies.

An opaque coating on the TBC surface is required for measurement of thermal diffusivity. Detailed inspection of samples measured to $1000^{\circ} \mathrm{C}$ revealed that the platinum coatings used last year (graphite and $\mathrm{Au} / \mathrm{Pd}$ have also been used) may lose opaqueness after repeated measurement and exposure to high temperature. Tungsten coatings were evaluated and did not lose opaqueness after exposure to $1000^{\circ} \mathrm{C}$. Measured thermal diffusivity of TBC coated with tungsten was identical to thermal diffusivity of TBC coated with platinum.

\section{Plans for Next Quarter}

\section{Furnace Cycle Test}

Furnace cycle testing at $1038^{\circ} \mathrm{C}\left(1900^{\circ} \mathrm{F}\right)$ will continue. In addition, samples that were furnace cycle tested at $1093^{\circ} \mathrm{C}\left(2000^{\circ} \mathrm{F}\right)$ in 1997 will be examined using the laser ultrasound $\mathrm{NDE}$ technique prior to tensile testing.

\section{Thermomechanical Fatigue Testing}

Samples will be prepared for TMF testing to provide data needed to predict TBC life at temperatures below $1038^{\circ} \mathrm{C}\left(1900^{\circ} \mathrm{F}\right)$. Test specimens for mechanical tests will be machined from GTD111, GTD222, Hast-X, and N5 substrates and then sprayed with TBC. Some sprayed specimens will be furnace-aged at various temperatures and times prior to testing.

\section{Thermal Conductivity}

Long-term sample aging will continue.

Thermal conductivity of TBC sprayed with powder from different suppliers will be evaluated. 


\section{Technology Application}

A database will be established that will link TBC properties and durability in laboratory tests to TBC durability in the ATS turbine. This database will be used ultimately to predict TBC life as a function of temperature and strain at specific locations on ATS turbine components. The database will also be used to identify process improvements to the baseline TBC that result in improved properties and durability.

\section{Section 2.3 (CC) Combined Cycle Integration}

\section{Section 2.3.1 (CCUA) Unit Accessories}

\section{Objective}

Development of four new unit accessories - fuel heating, cooling-air cooling, steam cooling, and clearance control-is critical to the development of the ATS gas turbine in order that the gas turbine meet its performance goals and function properly. The cooling-air cooling system is required to maintain temperature within sections of the gas turbine within acceptable limits. The steam cooling system is required to cool the turbine hot gas path parts while meeting performance goals for the ATS gas turbine. The clearance control system also enables the turbine to operate at a higher efficiency than would be possible without it. The exhaust diffuser will be designed so that maximum possible pressure recovery will be realized, thus increasing the performance of the ATS gas turbine.

Designs of remaining accessory systems will be conventional.

\section{Progress for this Quarter}

\section{Cooling-Air Cooling System}

The skid supplier chosen for the cooling-air cooling skid developed preliminary layouts for the skid components in order to work toward a detail design of the system. A design review was held in which GE Engineering provided additional design information to the supplier and reviewed the supplier's progress on the skid thus far. Toward the end of 1Q98, the interconnect piping design, being produced by GE Power Plant Engineering, dictated a change in the skid configuration so that the skid layout would better suit the interconnect piping design needs. A follow-up review was held with the supplier to reconfigure the cooling-air cooling skid based on the interconnect piping design input.

\section{Steam Cooling System}

An NPI Tollgate 3 conceptual design review of the steam cooling system was held for review of the steam delivery system, including the system on-base piping, flow measurement, condensate drains, and materials. A final configuration for the flow measurement system was agreed upon. Stress analysis for the steam delivery system was completed. Layout and design of the balance of plant steam cooling piping began.

\section{Clearance Control System}

The detail design of the clearance control skid was completed by the supplier working with GE Engineering. Manufacture of the skid components, as well as the skid base, was 
completed. The system components were installed on the skid base, and installation of the onbase piping and system valves was completed. Prior to shipment, all major components of the skid were tested for operation; the piping systems were checked for leaks and pressurized to full operating pressure; and all valves were operated and checked for response time. The skid was shipped to the GE Greenville, SC, facility for use in the $9 \mathrm{H}$ gas turbine FSNL test.

\section{Exhaust System}

The layout of the exhaust diffuser was developed in order to accommodate installation of the steam cooling piping by using removable panels. A redesign of the diffuser inner barrel was required to accommodate piping installation. Design of the interface between the diffuser and the steam piping was developed, which drove changes to the diffuser flowpath in order to provide space for the piping penetrations through the diffuser. In addition, it was determined that four support legs were not necessary to support the diffuser, thereby enabling elimination of the two forward support legs from the diffuser design. Further testing was conducted at CRD to determine whether the acoustic tones found in the diffuser model test at the end of 1997 were due to the diffuser flowpath design or unique to the test model. These tests were inconclusive in 1 Q98 and will continue into 2 Q98.

\section{Plans for Next Quarter}

\section{Cooling-Air Cooling System}

The preliminary layout of the latest cooling-air cooling skid (layout to be compliant with the interconnect piping design requirements) should be completed by the supplier in $2 \mathrm{Q} 98$. GE Engineering will hold a design review with the supplier to evaluate this layout. If approved, the supplier will begin detail design of the skid and its components. In addition, a separate study will be done to review the feasibility of using air from the cooling-air cooling system for the combustion purge air system.

\section{Steam Cooling System}

The layout of the startup air cooling portion of the steam cooling system will be developed. Further details of the steam delivery system will be developed and supplier selection for the system components will begin.

\section{Clearance Control System}

The clearance control skid will be installed in the $\mathrm{H}$ machine test stand at the GE Greenville, SC, facility. Prior to operating with the gas turbine, the skid will be operated independently of the turbine to test the system at full flow and temperature in conjunction with the test stand lube oil system, cooling water system, and control system. Next the gas turbine will be included in the circuit in order to test the system's effect on the turbine. During this test the turbine will not be in operation. The system will then operate during the first FSNL test of the $9 \mathrm{H}$ gas turbine, which will occur during $2 \mathrm{Q} 98$.

\section{Exhaust System}

A general design review will be held within GE Engineering for review of the exhaust diffuser design and the integrated steam cooling piping design. Once the diffuser preliminary design is approved, GE Engineering and Drafting will complete design drawings of the exhaust diffuser 
to use in working with the supplier to develop the detail design of the exhaust diffuser. CRD will continue its testing to determine whether the acoustic tones found during previous model tests are due to the diffuser flowpath design or to problems unique to the test model.

\section{Technology Application}

Development of the cooling-air cooling system, the steam cooling system, the clearance control system, and the exhaust diffuser system are all critical to successful operation of the ATS gas turbine. Each system is also critical to the high efficiency rating that the ATS gas turbine will achieve. Therefore, development of these systems will continue in order that the ATS gas turbine meet these design goals.

\section{Section 2.3.2 (CCCL) Controls}

\section{Objective}

An integrated plant control system will be developed and designed that will be suitable for the advanced gas turbine combined cycle power plant. Specifications of control equipment requirements will be prepared. Control and protection strategies will be developed for gas turbine steam cooling and integration with the steam turbine and heat recovery steam generator (HRSG). Control system dynamic behaviors will be studied by dynamic simulations. Specifications of control algorithms will be prepared for implementation in the control system program.

\section{Progress for this Quarter}

Control algorithms are being coded into control system programs, and control loop dynamic studies are being performed, including: gas turbine clearance control, variable guide vane control, fuel control, and startup and shutdown sequences. Development of algorithms for the protection of the ATS gas turbine continues, focusing particularly on the protection of hot gas path components. Design and manufacturing processes for the prototype control panels of the integrated control system are nearing completion. Prototype field testing of the control components is ongoing. Preparations were completed for FSNL testing.

\section{Plans for Next Quarter}

Study of control loop dynamics will continue. Software algorithms and sequence logic for the gas turbine will be coded into control programs in preparation for running tests. Verification of the control programs will continue, using equipment models and actual control panels. Manufacture of the prototype panel for gas turbine control will be completed.

\section{Technology Application}

The integrated plant control system conceptual design for the STAG $107 \mathrm{H}$ configuration will be very similar to that of the STAG $109 \mathrm{H}$ ATS plant. 
Section 2.3.3 (CCRA) Reliability, Availability, and Maintainability (RAM) Analysis

\section{Objective}

An evaluation of the reliability, availability, and maintainability (RAM) of the $7 \mathrm{H}$ equipment will be performed. The basis for the work will be the Electric Power Research Institute (EPRI) High Reliability Controls and Accessories Study. The RAM analysis will include: the flange-to-flange gas turbine, heat recovery steam generator, steam turbine, controls and accessories, electrical generator, and balance of plant equipment. A failure modes effects analysis (FMEA) will be included.

\section{Progress for this Quarter}

Activity during this period was restricted to FMEAs.

Gas Turbine Flange-to-Flange - Turbine and Compressor

9H FMEA development continued on all conventional aspects of the turbine and compressor. Sixty-one FMEAs were identified to-date in Gas Turbine Flange-to-Flange: 58 are component FMEAs and 3 are assembly FMEAs. A new category of FMEAs-system FMEAs-is being developed: 14 were identified, with another 20 possible. None were started. It is assumed that the $7 \mathrm{H}$ model will require the same number of component, assembly, and system FMEAs as the $9 \mathrm{H}$. No formal program was started.

\section{Plans for Next Quarter}

FMEA development will continue on the following: stator system, combustion, stator structures, steam delivery system, rotor, and assembly FMEAs involving the interface of Turbine Design Engineering and Compressor and Structures Design Engineering. A formal 7H FMEA program will be developed.

\section{Technology Application}

The FMEA results will be applied to the design of the $9 \mathrm{H}$ and $7 \mathrm{H}$ hardware, with special emphasis on the components involved with the steam-cooling aspects of the design.

\section{Section 2.3.4 (CCSD) Combined Cycle Systems Design}

\section{Objective}

Combined cycle system optimization analyses will be performed for cost/performance characteristics of the total plant. Steady-state modeling will be used to calculate the detailed plant performance. Dynamic modeling of load change sequences (e.g., startup and load rejection) will be used to specify control system design and assess operability.

\section{Progress for this Quarter}

Detailed HRSG optimization and cost/performance trade-off studies were initiated. Verification of the gas turbine cycle deck was carried out in order to support the FSNL test schedule. Work continued on system operating limits and control strategy definition for use in the $9 \mathrm{H}$ gas turbine prototype. Work on improving speed and convergence of the steady state performance model (SSPM) is ongoing. 
The thermal dynamic model (TDM) was updated with a computationally faster transient gas turbine model that includes compressor operating characteristics reflecting compressor test data, updated stage-by-stage turbine characteristics, and combustor characteristics. The development of a combined cycle model on a new platform is $70 \%$ complete. It includes the new reheater configuration for improved steam turbine admission temperature matching and optimized high-pressure/intermediate pressure (HP/IP) and low-pressure (LP) economizers. The new controls system includes revised startup procedures to protect the steam turbine from overheating during opening of steam turbine admission control valves. TDM results were provided to the gas turbine steam cooling piping design team to aid in the mechanical design of the gas turbine steam cooling piping system.

\section{Plans for Next Quarter}

Optimization studies for HRSG as well as other systems will continue. Improvements and extensions to the performance model will continue to enable automation of design point calculations. Work will continue on system operating limits and control strategy definition for use in the $9 \mathrm{H}$ gas turbine prototype.

An up-to-date model of the control system will be incorporated into the detailed plant TDM on the new computing platform, and three transient scenarios (hot start, normal shutdown, and trip) will be simulated for verification of the modeling. The TDM will be updated to include transient cycle deck with heat soak capabilities.

\section{Technology Application}

Operability evaluation of the STAG $109 \mathrm{H}$ configuration will be directly applicable to the STAG 107H ATS plant. Cooling-air cooling and fuel heating system conceptual designs will be very similar for the STAG $107 \mathrm{H}$ ATS plant.

\section{Section 2.4 (MF) Manufacturing Equipment and Tooling}

\section{Objective}

The materials, equipment, tooling, and processes required to produce the $7 \mathrm{H}$ and $9 \mathrm{H}$ turbines will be identified, designed, and procured. Manufacturing schedules will be established to support ATS pre-commercial demonstration goals. Manufacturing schedules and cost will be defined.

\section{Progress for this Quarter}

The IN718 turbine rotor forgings and some steam system components were completed and assembled into a turbine rotor at the GE Greenville, SC, facility. The turbine rotor was married to the compressor rotor, and the unit rotor was successfully balanced and assembled into the turbine.

Construction of a test stand for FSNL testing of $\mathrm{H}$ design gas turbines progressed to support turbine delivery for test hookup in April. All major accessory equipment, test stand components, and electrical and control equipment were delivered and installation was started. 


\section{Plans for Next Quarter}

Test Stand \#8 will be completed, the initial $9 \mathrm{H}$ turbine will be transported to the test stand, and FSNL testing will be accomplished.

\section{Technology Application}

Development of the turbine wheel forging dies and the ultrasonic inspection techniques are the first application in forgings of this size and will be used to provide high-strength, hightemperature material that is compatible with the steam cooling environment in the ATS turbine rotor. The mockups are being used to ensure fit-up of ail components in very restrictive areas of the turbine. An electronic simulation of these areas is being done in parallel to develop simulation technology for future applications. The TBC robot controllers will provide the thickness control for the TBC coating that is required for proper heat transfer properties in the steam-cooled turbine airfoil components.

\section{Section 2.5 (IG) Integrated Gasification and Biomass Fuel}

\section{Objective}

An assessment of the ATS will be performed as part of an efficient and environmentally compatible integrated gasification combined cycle (IGCC) power generation system. Modifications to the gas turbine to accommodate the high mass flow resulting from the low heating value fuel gas and nitrogen injection for low NOx emissions will be identified. Analyses will be run to optimize the integration of the steam cycle with one oxygen-blown entrained flow gasifier and gas cleanup system and integration of the gas turbine with the air separation unit. IGCC system performance will be analyzed for one coal composition at ISO ambient air conditions.

\section{Progress for this Quarter}

There was no activity associated with this task under the ATS Phase 3 Cooperative Agreement during the current reporting period.

\section{Plans for Next Quarter}

There is no activity planned for this period.

\section{Section 2.6 (DE) Pre-Commercial Demonstration}

\section{Objective}

A commercial proposal will be prepared and submitted to the host utility.

\section{Progress for this Quarter}

Commercial activity remains high. Excess generating capacity in the domestic market continues to delay project approvals; however, commercial discussions (equity, price, shipment requirements, insurance premiums, performance levels, construction financing, and service agreements) with potential host utilities and power marketers continue to intensify. 


\section{Plans for Next Quarter}

The next Utility Advisory Board (UAB) meeting is planned for May 1998 to coincide with the $9 \mathrm{H}$ gas turbine FSNL testing in $2 \mathrm{Q} 98$.

\section{Section 2.7 (PM) Program Management}

\section{Objective}

Within GEPS Engineering, an ATS Program Office will be established and a Program Manager and a Contract Administrator will be assigned. The Program Manager will direct the overall activities of the Program Office, and will have responsibility for reporting to DOE and ensuring that the program goals are achieved. The Program Office is responsible for communicating contract requirements, authorizing applied labor and expenses for material and services, scheduling, monitoring, and reporting cost and technical performance. Additional responsibilities include coordinating ATS activities with CRD and GEAE. The assigned Contract Administrator will support the Program Manager in all administrative matters. All materials and equipment acquisitions will be closely monitored by the Program Office with support from the Finance and Sourcing organizations.

Actual scope, schedule, and budget will be tracked against plan. An integrated program plan will be maintained, including a detailed Work Breakdown Structure, that accurately describes the planned work, reflecting all changes in work scope or schedule. The integrated program plan includes the implementation and coordination of all program support procedures and initiatives such as Target Costing, Key Quality, and Design for Manufacturing.

Reports will be prepared to serve both DOE and GE needs for oversight and monitoring, including quarterly reports, annual reports, and topical reports. A final report will be prepared at the completion of the cooperative agreement. Reports specified in the Cooperative Agreements Financial Assistance Reporting Requirements Checklist will be supplied. Technical papers will be submitted for presentation to professional society meetings. Open communications will be maintained with DOE and the Industry Advisory Board.

\section{Progress for this Quarter}

The Department of Energy and GE Power Systems concluded negotiations for a restructured ATS program that deleted the host utility site operation phase (Phase 4), and extended the technology validation phase (Phase 3) through FSNL testing of the $7 \mathrm{H}$ gas turbine.

\section{Plans for Next Quarter}

A Program Review is scheduled to be held at GE Aircraft Engines, Evendale, Ohio, in order to tour the full-scale combustion development test stand (A2) and the full-scale nozzle cascade test stand (A3).

Planning will begin for the Budget Period 3 cost proposal to cover calendar 1999. 


\section{SECTION 2 TECHNICAL PROGRESS REPORTS: COMPLETED TASKS}

\section{Section 2.1 (NE) NEPA}

\section{Objective}

A draft topical report was prepared that provided the environmental information associated with Phase 3, Technology Readiness Testing, as specified in the National Environmental Policy Act (NEPA). DOE used this information to prepare the NEPA documentation for Phase 3. DOE reviewed the report and advised the participant of its acceptability. A final report was then submitted.

A second draft topical report was prepared that provided the environmental information associated with Phase 4, Pre-Commercial Demonstration, as specified in NEPA. DOE used this information to prepare the NEPA documentation for Phase 4. DOE reviewed the report and advised the participant of its acceptability. A final report was then submitted.

At DOE's request, Phase 4 was deleted and Phase 3 was restructured (as Phase 3R) with the inclusion of the $7 \mathrm{H}$ FSNL test at GE Greenville, SC, facility. This change necessitated the generation of an environmental assessment of the Greenville assembly and test facility.

\section{Plans}

This task was completed in 4Q97.

\section{Technology Application}

The NEPA report provides documentation that GE Power Systems is in compliance with all applicable environmental, health, and safety laws and regulations, and has the required permits and licenses necessary for compliance.

\section{Section 2.2.1 (GTAD) Aerodynamic Design}

\section{Objective}

To achieve ATS performance goals, a four-stage turbine was designed. Advanced aerodynamic technology (sometimes called 3D aerodynamics) pioneered at GEAE was applied to each stage to maximize performance and meet mechanical design requirements required by steam cooling technology.

The $7 \mathrm{H}(60 \mathrm{~Hz})$ and $9 \mathrm{H}(50 \mathrm{~Hz})$ turbines have similar flowpaths and a common rotor but require different aerodynamic designs. Performance requirements for the $7 \mathrm{H}$ and $9 \mathrm{H}$ turbine aerodynamics are the same.

\section{Plans}

This task was completed in $4 \mathrm{Q} 96$. 


\section{Technology Application}

Advanced aerodynamic technology (sometimes called 3D aerodynamics) pioneered at GEAE was applied to each stage to maximize performance and meet mechanical design objectives required by steam cooling technology.

\section{Section 2.2.2.3.1 (GTFFTR) Turbine Rotor Mechanical Analysis}

\section{Objective}

The objective of this task is to provide thermal and mechanical design and analysis support for rotor components of the ATS gas turbine. Analyses are run to determine temperature, displacement, and stress distributions for various components of the ATS gas turbine rotor. Initial designs and concepts are analyzed, compared, and modified to meet design specifications with respect to stress levels, low cycle fatigue (LCF) life, yielded volume, residual displacement, rabbet closure, etc.

\section{Plans}

This task was completed in $4 \mathrm{Q} 97$.

\section{Technology Application}

The analysis performed and the resulting design features will be used to robustly design an ATS gas turbine rotor that meets cycle life requirements.

\section{Section 2.2.2.3.2 (GTFFTR) Wheel Forging Residual Stress Analysis}

\section{Objective}

The objective of this task is to determine the influence of residual stresses on overspeed design limits for IN706 and IN718 wheel forgings. Overspeed tests on a 7F first-stage wheel (IN706) indicated that there might be large residual stresses in the wheel forgings after heat treatment. These residual stresses may have an effect on fatigue life and will affect residual displacements. The effect on residual rabbet deflections is particularly important since this may affect rabbet opening/closure as well as rabbet loading and local plasticity. If residual stresses turn out to be significant in the ATS machine (IN718) as well, they will have to be included in the design calculations. The residual stress calculation will be done on the $7 \mathrm{~F}$ wheel first to correlate the analysis with available test data. The procedure will then be applied to the ATS wheels.

\section{Progress for this Quarter}

This task was completed in $4 \mathrm{Q} 97$.

\section{Technology Application}

Residual stress levels will affect the deformation of the wheel during overspeed and can affect fatigue performance. If significant residual stresses remain after the aging process, the residual stresses will be included in the design calculations. 


\section{Section 2.2.2.4.1 (GTFFTB) S1B and S2B Wheel Dovetail Analysis}

\section{Objective}

The objective of this task was to perform 3D thermomechanical analyses of ATS gas turbine rotor dovetails, bolt holes, and steam-cooling holes. The dovetails are highly stressed and, in addition, there are severe thermal gradients in the dovetail region. Detailed 3D stress analyses are required to ensure that the dovetails and the wheels meet design guidelines.

\section{Plans}

This task was completed in $2 \mathrm{Q} 97$.

\section{Technology Application}

The dovetails were highly stressed and, in addition, there were severe thermal gradients in the dovetail region. Detailed 3D stress analyses were required to ensure that the dovetails and the wheels meet design guidelines for the ATS turbine rotor.

\section{Section 2.2.2.4.2 (GTFFTB) S3B and S4B Tip Shroud Design Optimization}

\section{Objective}

The objective of this task was to optimize stresses and creep deflections in the ATS third- and fourth-stage bucket shrouds. Detailed 3D creep analyses were needed to ensure that the stresses were within the required limits for creep life.

\section{Plans}

This task was completed in $3 \mathrm{Q} 97$.

\section{Technology Application}

The analysis performed here was incorporated into the shroud designs of the ATS gas turbine third- and fourth-stage buckets.

\section{Section 2.2.2.4.3 (GTFFTB) Bucket Wide Grain Sensitivity Analysis}

\section{Objective}

The objective of this task was to show the effect on natural frequency of the variations in grain size and orientation of $9 \mathrm{H}$ fourth-stage buckets. If the variations in natural frequency could be shown to be non-critical, bucket yield would be improved.

\section{Plans}

This task was completed in 1Q97.

\section{Technology Application}

The results of this study were used on the ATS gas turbine design primarily as a means of improving bucket yield. 


\section{Section 2.2.2.4.3.1 (GTFFTB) Bucket Robust Design and Life Assessment}

\section{Objective}

The objective of this task is to use finite element analysis and Design of Experiments techniques to quickly estimate bucket life, identify optimized bucket critical-to-quality criteria (CTQs), and statistical distributions of bucket CTQs given statistical distributions of bucket parameters. The main reason for doing this work is to obtain robust bucket designs that are minimally sensitive to manufacturing tolerances and will therefore meet all life requirements.

\section{Progress for this Quarter}

This task was completed in 4Q97.

\section{Technology Application}

The results of this study will be used on the ATS gas turbine in order to assess bucket performance and obtain optimized factor settings and statistical distributions of the CTQs given the distributions of the factors. The results of this study will be used on the ATS gas turbine design primarily as a means of improving bucket yield.

\section{Section 2.2.2.4.5 (GTFFTB) S1B and S2B Air/Steam Coolant Transition Analysis}

\section{Objective}

The objective of this task was to determine the time required for switching from air cooling to steam cooling to keep thermal stresses in the ATS gas turbine first-stage and second-stage buckets within acceptable levels. Three-dimensional transient thermomechanical analyses of the first- and second-stage buckets were run during the transition from air to steam cooling. Predicted temperature and stress responses were used to evaluate the effect of the coolant change on the bucket lives and to recommend control system modifications, if necessary.

\section{Plans}

This task was completed in $2 \mathrm{Q} 97$.

\section{Technology Application}

This analysis showed that air-to-steam transition requirements during startup will have to be controlled in order for the LCF life of the buckets to meet design guidelines.

\section{Section 2.2.2.5.1 (GTFFTS) Turbine Stator Robust Design}

\section{Objective}

The objective of this work is to develop and apply robust design methods for the development of steam-cooled components of the advanced gas turbine. The goal of this effort is to achieve high standards of performance, quality, and reliability for these components by performing the following tasks during the product development cycle: (1) apply, and develop as needed, the robust design methodology to first- and second-stage nozzles; (2) apply the robust design methodology to some of the steam- and air-cooled stator components (e.g., first-stage shroud 
and turbine inner shell); (3) provide consulting and support for applying the robust design methodology to some of the critical rotor components (e.g., manifold, steam tube bushings, and spoolie); (4) provide consulting and support for integration of design, manufacturing, and assembly; and (5) train the GEPS staff on the concepts, methods, and tools for achieving robust design.

A "robust design" is a design that satisfies the product performance requirements in an optimal manner and also exhibits minimal sensitivity to variabilities arising from various sources, such as manufacturing processes and tolerances, material behavior, operating environment, in-service damage, and maintenance and repairs. The methodology consists of the following key steps: (1) identification of critical-to-quality (CTQ) characteristics, key control parameters (KCPs), and key noise parameters (KNPs); (2) definition of the Design of Experiment matrices for KCPs and KNPs; (3) execution of the Design of Experiment matrices through analysis, testing, prototyping, and/or manufacturing; (4) statistical analysis of the Design of Experiment data to develop response surfaces, (5) optimization using response surfaces to determine optimal $\mathrm{KCPs}$ that meet the $\mathrm{CTQ}$ requirements and minimize sensitivity to variations; (6) performing Monte Carlo analysis to quantify the likelihood of meeting CTQ requirements under various noise conditions; (7) improving the part's producibility and assembly by specifying wide manufacturing and assembly tolerances; and (8) validating the design developed through analysis and/or testing. The methodology was demonstrated successfully on a number of real-life complex applications and is being applied in the present project to steam-cooled components of the ATS gas turbines.

\section{Plans}

This task was completed in 4Q97.

\section{Technology Application}

Many results from the robust design studies described above were incorporated in drawing releases and are also being used to enhance the producibility of steam-cooled parts. Response surfaces are being utilized for assessing the LCF life of cast parts, and robust design methodology has been applied by the design engineers to other components of ATS gas turbine.

\section{Section 2.2.2.6.1 (GTFFSTEF) Exhaust Diffuser Performance}

\section{Objective}

The requirements for the ATS gas turbine exhaust diffuser include: (1) improved baseload pressure recovery performance compared with earlier GE exhaust diffuser designs and (2) operation without acoustic resonance at any operating point of the gas turbine. The objectives of this task were to test potential ATS gas turbine exhaust diffuser geometries for pressure recovery performance and to verify that the design selected did not excite acoustic resonances.

The test program included the installation and test of a scale-model diffuser with flowpath geometries and components compatible with the ATS gas turbine. Specifically, the cost-saving idea of internal insulation required axial ribs in the walls of the diffuser flowpath. Impact on 
pressure recovery was measured. Several other tests were performed, each with the aim of maximizing performance. These tests included examining variations in flowpath, centerbody length and termination shape, steam pipe locations and fairings, and other diffuser features that affect performance. The final exhaust diffuser design was tested to verify that no acoustic resonances are excited, particularly at FSNL conditions.

\section{Plans}

This task was completed in 4Q97.

\section{Technology Application}

The results from this series of scale-model gas turbine exhaust diffuser tests were used to establish several diffuser design features. One of these features was the feasibility of an internally insulated exhaust frame, a less expensive option than external insulation. Data were used to design a diffuser with the required pressure recovery, enhancing the overall combinedcycle plant efficiency. These tests verified that the final design was free from acoustic resonances.

\section{Section 2.2.2.6.2 (GTFFST) Steam Box CFD Analysis}

\section{Objective}

The objective of this task was the design of a steam delivery system as part of the $9 \mathrm{H} / 7 \mathrm{H}$ steam cooling design. A steam gland was designed to bring the cooling steam from a stationary inlet pipe onboard a rotating shaft. Steam entered the steam gland through an axial inlet pipe. The pipe turned $90^{\circ}$ so that the resulting flow traveled tangent to the rotor shaft and into an inlet scroll. The inlet scroll cross-sectional area was sized to match the steam velocity to the rotor tangential velocity. As the steam traveled around the scroll circumferentially, some steam was extracted into rotor slots. A 3D CFD analysis was required

to define the appropriate geometry of the steam gland inlet scroll that resulted in a nearly uniform radial outflow from the scroll circumference.

\section{Plans}

This task was completed in $4 Q 96$.

\section{Technology Application}

The results of this study have had an impact on the design of the scroll geometry and confirmed its proper performance in meeting the desired uniform flow distribution. The analysis of the entrance to the rotor served three purposes: it incorporated rotational effects and confirmed the 1D analyses of the YFT study of the steam distribution system; it pointed to the relative insensitivity of the current design to variation in the inlet conditions of the flow; and, with the prediction of the relative swirl angle, obstacles in the annular passage were designed to be aligned with the incoming steam. 


\section{Section 2.2.3.1.1 (GTETNC) Nozzle Cascade CFD Analysis}

\section{Objective}

The objective of this task was to apply a fully viscous 3D CFD analysis to predict the flow and aid in the generation of heat transfer boundary conditions for the first-stage Nozzle Cascade

Test. Such a validated CFD tool then became the vehicle to apply the Nozzle Cascade Test data to the actual machine design problem.

\section{Plans}

This task was completed in $1 \mathrm{Q} 96$.

\section{Technology Application}

The validation of NOVAK3D predictive capabilities provided a valuable tool to evaluate the impact of design modifications and off-design performance of ATS nozzles in particular. It also contributed to a more realistic calculation of heat transfer coefficients and consequently enhanced the heat transfer predictions in complex geometries.

\section{Section 2.2.3.1.2 (GTETEH) Combustion-Generated Flow Effects on Heat Transfer}

\section{Objective}

The objective of this task was to evaluate the freestream turbulence intensity incident upon the ATS first-stage nozzle airfoil, and the effect of this turbulence level on the airfoil heat load. This turbulence intensity level and its character have a major and direct bearing on the heat load for the nozzle airfoil and endwall.

\section{Plans}

This task was completed in $4 \mathrm{Q} 96$.

\section{Technology Application}

The ATS cascade test results were incorporated directly into the ATS first-stage nozzle design. Comparison of results with both high-turbulence-generating perforated plates and a DLN combustor system cold-flow mockup verified the applicability to design of heat transfer results from the former method.

\section{Section 2.2.3.4.2 (GTETRH) Bucket Cooling Circuit Rotational Pressure Drop Test Objective}

The objective of this task was to determine the effect of rotation on the pressure drop in a radial bucket cooling passage. The CFD computations of the effect of rotation on bucket cooling passage heat transfer and pressure drop indicated a significant effect of the Buoyancy number on pressure drop. Since the bucket pressure drop is a major fraction of the total system pressure drop involving the coolant, it was deemed necessary to measure this effect using the full-scale test rig. 
The high aspect ratio turbulated duct assembly was instrumented to measure the pressure drop between the inlet and outlet manifolds. Appropriate heaters were employed on the pressure measurement lines to avoid condensation of the working fluid and to minimize the density corrections required due to temperature differences between the measurement lines and the test duct. This allowed the differential pressure transducer to be mounted near the rotational axis, where no transducer correction for centrifugal effects was required. The pressure drop for both outflow and radial inflow was measured.

\section{Plans}

This task was completed in 3Q96.

\section{Technology Application}

The new pressure drop correlation, which includes the effect of the Buoyancy number, is now in use in the evaluation of alternate coolant passage designs and in the evaluation of the flowpressure drop characteristic of the ATS turbine bucket cooling system.

\section{Section 2.2.3.5.1 (GTETS2NHT) S2N Trailing Edge Flow Test}

\section{Objective}

The objective of this task was to perform heat transfer tests in the trailing edge region of the second-stage nozzle using a Plexiglas ${ }^{\mathrm{TM}}$ model built in 1995 . The purpose of the work was to generate a cooling scheme that will (1) even out the coolant side heat transfer coefficients along the channel and (2) yield results that are comparable to or better than the turbulent pipe flow correlation predictions.

The model kept the important geometric variables of the passage close to the actual design. It had thin-foil heaters on both the suction and pressure sides, and liquid crystals to determine the temperature distributions. Tests were planned to investigate the triangular passage performance with several turbulator designs.

\section{Plans}

This task was completed in 3Q96.

\section{Technology Application}

The test results for cooling passages in the second-stage nozzle trailing edge cooling circuit provided the necessary design information and turbulator configurations for the ATS secondstage nozzle. This allowed the design to obtain the desired heat transfer enhancement for the passages and to channel the cooling flow near the apex of the triangular flow passage near the trailing edge region effectively.

\section{Section 2.2.3.5.3 (GTETIH) S1N Outer Band Liquid Crystal Heat Transfer Tests}

\section{Objective}

The objective of this task was to perform heat transfer tests with a representative outer band impingement configuration and measure the heat transfer coefficient distributions underneath 
the impingement jets. The data were compared with the design calculations and expectations. A test rig was used to simulate the design impingement jet plate geometry as closely as possible. The test section walls were instrumented with three etched thin-foil heaters and a liquid crystal layer to measure the local wall temperature distributions as a function of flowrate and heat flux. The temperature data were then converted into heat transfer coefficient values.

\section{Plans}

This task was completed in 4Q96.

\section{Technology Application}

The test results obtained with the flow and heat transfer tests showed that the design calculations and models were able to successfully predict the flow directions and heat transfer coefficients for the complicated impingement pattern of the ATS first-stage nozzle outer band. The tests also showed that the heat transfer is dependent on the leading and trailing edge cavity discharge pressure levels. In addition, the data showed that an impingement design without a separating rib is more effective than a design with a separating rib on the suction and pressure sides.

\section{Section 2.2.3.5.4 (GTETIH) S1N Convex Cavity Heat Transfer Tests}

\section{Objective}

The objective of this task was to perform flow and heat transfer tests in a simple test rig representative of a first-stage nozzle convectively cooled passage geometry with two different turbulator designs to determine the effect of corner radius on the heat transfer enhancements obtained with the turbulators. Two simplified plastic models of the cooling channel were constructed with the important geometric variables kept as close as possible to the actual design. An additional test section was also constructed to model the exact geometry of the convectively cooled cavity, which incorporated the area changes along the radial distance. The inside surfaces of the test pieces were coated with liquid crystal paint or a liquid crystal sheet, and transient and steady-state tests were run to determine the friction factors and local heat transfer coefficient distributions. The results were also compared with the CRD database. An additional flow test was conducted with a metallic test section manufactured with exactly the same dimensions as the prototypical passage to verify the flow models of the design.

\section{Plans}

This task was completed in 4Q96.

\section{Technology Application}

The results of these tests with rectangular and filleted turbulated tubes provided the designer with information on the differences between the two and showed that the database can be used to predict the friction and heat transfer. The results with various turbulator heights changed the design requirements to prevent large variations in the local heat transfer coefficients. The test data also showed that the heat transfer enhancements are not reduced at the high Reynolds numbers of interest for the present design. 


\section{Section 2.2.3.5.5 (GTETIH) Bucket Tip Closed Circuit Cooling}

\section{Objective}

The objective of this task was to measure non-rotating heat transfer and pressure drop in the $180^{\circ}$ tip turn region of a two-pass serpentine bucket tip, and to evaluate the ability of an enhanced surface in the tip region to enhance the tip cooling without a substantial pressure drop penalty.

\section{Plans}

This task was completed in 3Q96.

\section{Technology Application}

These results were used by the designers of the ATS gas turbine buckets to design the tip turn regions of serpentine cooling circuits.

\section{Section 2.2.3.5.6 (GTETLE) Bucket Leading Edge Heat Transfer Testing}

\section{Objective}

The objective of this task was to evaluate turbulator geometries for the first-stage bucket leading edge passage by performing non-rotating heat transfer and pressure drop tests at high Reynolds numbers on scaled models of the leading edge passage.

\section{Plans}

This task was completed in $4 \mathrm{Q} 96$.

\section{Technology Application}

The heat transfer and pressure drop results from this task were used in the design of the firststage bucket in the ATS gas turbine.

\section{Section 2.2.3.5.7 (GTETH) S1N Surface Enhanced Internal Heat Transfer}

\section{Objective}

The objective of this task was to investigate and determine the heat transfer coefficient enhancements that could be generated under impingement jet cooling modules by adding surface roughness elements without increasing the total system pressure drop. The effect of bumps missing in some regions due to manufacturing problems will also be investigated.

The test section used for impingement heat transfer tests was enclosed in a high-pressure enclosure that could be operated at pressures up to 10.2 atm (150 psia) by means of a backpressure control valve. The impingement air was fed to a supply chamber equipped with a square impingement jet plate that could accommodate several hole configurations. The impingement test surface was in intimate contact with a copper block that was heated by four cartridge heaters. The impingement test plates, positioned at a controlled distance from the impingement jet plates, were instrumented with four embedded thermocouples that measured the plate temperature. Tests were conducted at various jet Reynolds numbers and several jet 
plate geometries. To investigate the effect of bumps missing in some regions, the highpressure containment was modified so that a window could be attached at one end. A thin-foil heater and a liquid crystal assembly were glued onto the impingement test plate and the color changes observed with the liquid crystal video thermography (LCVT) system.

\section{Plans}

This task was completed in $4 \mathrm{Q} 96$.

\section{Technology Application}

The ANSYS analysis results provide the increases in wall temperature expected for various numbers of bumps missing. The acceptable temperature rise will determine the quality control criteria and the nondestructive testing technique for the missing bump number determination. The transient technique provides a nondestructive technique to check the non-uniformity of the cooling and the number of missing bumps.

\section{Section 2.2.3.5.9 (GTETBKHT) High Reynolds Number Turbulator Static Heat Transfer Test}

\section{Objective}

The objective of this task was to investigate and determine the heat transfer coefficient enhancements possible in the first-stage nozzle. Internal cooling was supplied by two different types of convection: one using impingement heat transfer within the internal airfoil cavities, the other using high Reynolds number turbulated heat transfer within the aftmost convective channel of the airfoil. This task concentrated on the latter type of heat transfer. Experimental work reported in the open literature on turbulator heat transfer enhancement and friction factors is limited to passage Reynolds numbers below 80,000 . This task supplied data and correlations that were used for advanced machine design conditions. Heat transfer and pressure drop data were required at far higher Reynolds numbers than previously tested with common turbulator geometries and passage aspect ratios.

\section{Plans}

This task was completed in $4 \mathrm{Q} 96$.

\section{Technology Application}

The results from this task were applicable to any non-rotating components in the ATS gas turbine that used turbulated passages for cooling. As long as rotational effects were accounted for, these results were also applicable to turbulated passage cooling of rotating components.

\section{Section 2.2.3.5.10 (GTET) Impingement Degradation Effects}

\section{Objective}

The internal nozzle design verification tests conducted in 1996 with various impingement jet plates and test plates showed that the impingement heat transfer coefficients measured under the first and second rows of the impingement jets were lower than the open literature 
correlation predictions (Metzger). Although this difference was not significant in some regions, it was important in others where accurate knowledge of the heat transfer coefficients under the first two impingement jets is important. The differences between the design verification test results and the correlation predictions were attributed to the fact that in those tests the first row of jets was near a wall with zero velocity boundary conditions while in the correlation tests the first row was adjacent to a constant pressure boundary condition.

The objective of this task was to understand the physical phenomenon that causes the observed difference. The local static pressure distributions along the cross flow regions of the impinging jets were measured for two inlet boundary conditions, one with a wall and the other with a constant pressure. Tests were also conducted with the cross flow discharging in one direction across the impingement jets and discharging in two directions symmetrically from the center row.

\section{Plans}

This task was completed in $3 \mathrm{Q} 97$.

\section{Technology Application}

The results obtained clarified the discrepancy between prior test results and those from open literature correlation predictions (Metzger). The new data improved the design of the firststage nozzle internal cooling scheme.

\section{Section 2.2.3.6 (GTETEH) Surface Roughness and Combustor-Generated Flow Effects on Heat Transfer}

\section{Objective}

The effects of TBC surface roughness on external heat transfer was characterized using flat plates tested in an atmospheric wind tunnel. An advantage of flat plates over airfoils is that TBCs can be easily applied and polished to uniform thickness and surface finish. Full mapping of the TBC surface topography was performed to support Infrared mapping of the surface temperatures (heat transfer coefficients). Reynolds numbers spanned those expected in the ATS turbine inlet nozzle surface away from the leading edge. Tests included plates with and without leading edge step heights to model the effects of component interface misalignments. Verification tests on airfoil replicas were also performed.

\section{Plans}

This task was completed in $4 \mathrm{Q} 97$.

\section{Technology Application}

Application of the data obtained from this task takes on two forms within the design of the turbine airfoils. First, tests which measure the effect of TBC surface roughness on external heat transfer were used to determine the extent of necessary polishing for new parts. Second, detailed quantification of the heat transfer magnitude associated with actual TBC roughness allowed for more accuracy in the initial design of airfoils. The data obtained on flowpath steps were used directly in the design of the turbine nozzle sidewalls to assess the impact and 
consequences of heat transfer enhancement due to steps, including the effect of TBC roughness as a possible mitigating factor.

\section{Section 2.2.3.6.1 (GTETEH) S1N Heat Transfer for Production Aero with TBC Spall Effects}

\section{Objective}

The objective of this task was the quantification of the external heat transfer coefficient distribution for the production aerodynamic design definition of the ATS turbine inlet nozzle airfoil.

A previous task begun in Phase 2 and completed under Phase 3 quantified the external heat transfer distributions for the original aerodynamic design, including effects due to roughness and turbulence intensity. The production aerodynamic design was sufficiently different in crucial regions to warrant a new series of tests, again including roughness and turbulence intensity effects. The new aerodynamic definition for the nozzle was specifically designed to lower the heat load on the airfoil. Results from the previous cascade tests were used on the new airfoil design, but with the assumed validity of local Reynolds number scaling of heat transfer coefficients. Since such scaling of results had no experimental basis for airfoils that deal with complex flows, it was necessary to verify the new design. Results from the original series of tests were used to reduce task efforts to a minimum. Most of the original apparatus hardware from the ATS Turbine Inlet Nozzle Cascade was reused for this task.

Plans

This task was completed in 1 Q97.

\section{Technology Application}

The results from this series of tests yielded external heat transfer load validation on the production first-stage nozzle design.

\section{Section 2.2.3.6.2 (GTETEH) Surface Roughness Effects on Heat Transfer}

\section{Objective}

The external heat loading for the ATS first-stage nozzle aiffoil was heavily dependent upon the nonlinear effects of surface roughness, especially as the nozzle design could not rely upon film cooling. Given the current state of turbine cooling technology, the only viable method for determining the nozzle heat load with roughness effects was experimental validation of the heat transfer distribution under non-dimensional engine-representative conditions.

The ATS Turbine Inlet Nozzle Cascade was used to provide data on external heat transfer coefficients on airfoils with surface roughness. The cascade incorporated instrumented airfoils with flow conditions representative of the ATS inlet nozzle geometry. The appropriate nondimensional parameters for dynamic similarity were close to those of the engine inlet nozzle. External heat transfer coefficient distributions were measured through the use of embedded thermocouples, with a constant surface heat flux condition supplied by thin-foil heaters. Surface roughness elements of the appropriate size and distribution were bonded onto the 
surface heaters. Data included various roughness levels, distributions, and types to allow the calibration of predictive methods. Characterization of surface roughness effects included the interactive nature of roughness with fluid dynamic conditions such as acceleration. The cascade was also used to assess the effects of transition piece wake shedding on airfoil heat transfer, the effect of extreme surface roughness representative of as-sprayed thermal barrier coatings, and the effect of modeled coating spallation on heat transfer enhancements.

\section{Plans}

This task was completed in $3 \mathrm{Q} 96$.

\section{Technology Application}

The test results were used directly in the design of the ATS first-stage nozzle airfoil. Thus the cascade conditions for an appropriate rough surface condition, with elevated freestream turbulence intensity from a DLN combustor mockup, were used as the convective heat load definition for the nozzle airfoil. Since modeled spallation heat transfer enhancements were equal to or below the assumed enhancement levels for the nozzle design, the conservative nature of this portion of the design was verified. Cascade testing verified the requirement to polish the thermal barrier coating on the Full Scale Nozzle Cascade instrumented airfoils, thereby avoiding potential test problems in that task. The optimal relative location for the transition piece endwall segments, as determined through cascade testing, was incorporated into the turbine design.

\section{Section 2.2.4.2 (GTMTSO) Oxidation Due to Steam}

\section{Objective}

Testing of ATS materials in steam was performed to evaluate the long-term oxidation responses to this environment. Specimens were subjected to steam exposure in an autoclave and removed at specified intervals for examination of oxidation characteristics.

\section{Plans}

This task was completed in $4 \mathrm{Q} 96$.

\section{Technology Application}

This task was designed to evaluate the static behavior of turbine materials in a steam environment in order to take into account the introduction of steam cooling.

\section{Section 2.2.4.3 (GTMTCE) Corrosion Rate Evaluations of Airfoil Overlay Coatings Objective}

The objective of this task was to evaluate the performance of ATS materials in potentially corrosive environments with various overlay coatings and substrate materials. Initial evaluations were performed in small burner rigs with known contaminants. This allowed ranking of the corrosion rates of materials and coatings. Subsequent testing was performed in 
facilities that better simulate gas turbine service conditions, including high gradients, for confirmation of burner rig results.

Plans

This task was completed in 4Q97.

\section{Technology Application}

This task evaluated potential airfoil coatings in environments that reflect planned ATS turbine operating conditions.

\section{Section 2.2.4.4 (GTMTBV) Compressor Blades and Vanes Materials and Processes}

\section{Objective}

Although material selections have been completed, this task examined potentially less expensive materials for use in blades and vanes in the latter stages of the ATS compressor. These evaluations of alternate materials were based on results of tests of mechanical properties, with emphasis on HCF properties. For the materials that were selected, tests of critical properties were conducted under ATS-specific conditions. Component tests of select parts were conducted for life verification purposes and establishment of final manufacturing parameters.

\section{Plans}

This task was completed in 1Q97.

\section{Technology Application}

This task characterized the mechanical behavior of existing and new blade/vane materials in more aggressive environments than past compressor operation.

\section{Section 2.2.4.5 (GTMTVG) Compressor Variable Guide Vane System Design Support and Process Development}

\section{Objective}

Information to support selection of materials for the variable guide vane (VGV) bushings and thrust washers was gathered to ensure a robust and reliable design. Testing was conducted to confirm materials selections, cover any parameters outside of existing data, and gather data for new materials.

\section{Plans}

This task was completed in 2 Q97.

\section{Technology Application}

This task provided operational test data on ancillary materials used in the variable guide vane system. Potential bushing and sleeve materials will be screened. 


\section{Section 2.2.4.12 (GTMTST) Turbine Structures Materials and Processes}

\section{Objective}

Producibility evaluations for the turbine structures included selection of materials processing parameters and chemistry, and preparation of material and process specifications. Processing trials were used to confirm producibility and verify capabilities of suppliers. Testing will be conducted where necessary to evaluate the materials under ATS conditions.

\section{Plans}

This task was completed in $4 Q 97$.

\section{Technology Application}

This task contributed to the characterization of turbine structure materials in test conditions that reflect service environments.

\section{Section 2.2.4.13 (GTMTSH) Turbine Shells}

\section{Objective}

Materials and processes were identified for production of the turbine shells. Specifications were defined after material property testing and process verification/optimization trials were conducted to achieve the best quality part to meet all design criteria.

\section{Plans}

This task was completed in $4 \mathrm{Q} 97$.

\section{Technology Application}

This task contributed to the characterization of turbine shell materials in test conditions that reflect service environments.

\section{Section 2.2.4.14 (GTMTSR) Seal Technology}

\section{Objective}

Improved gas path seals were developed for the ATS turbine utilizing seal technology developed for aircraft engine components where applicable. The technology will be evaluated using developmental hardware and samples.

\section{Plans}

This task was completed in 4Q96.

\section{Technology Application}

This task optimized seal attachment processes focused on airflow leakage restrictions to enhance performance. 


\section{Section 2.2.4.14.1 (GTFFTSESV) Hot Gas Path and Transition Piece Cloth Seals}

\section{Objective}

Seals between the hot gas path turbine components are required to help meet the ATS combined cycle efficiency target. One objective of this task is to develop and test hot gas path seals that meet both leakage performance and life requirements. Specifically, improved sealing performance that reduces the equivalent gap of the seal is sought by replacing the current Q-tip seals with a cloth sealing system. The cloth seals also need to meet the same full-life requirement.

Seals between the combustor transition piece and the first-stage nozzle are required to help meet the ATS combined cycle efficiency target. The other objective of this task is to develop and test transition piece cloth seals that meet both leakage performance and life requirements. Specifically, advanced cloth seals will be developed for the transition-piece/first-stage-nozzle junction. Life consistent with the prescribed inspection interval is required.

\section{Progress for this Quarter}

This task was completed in $4 \mathrm{Q} 97$.

\section{Technology Application}

A turbine stator (shroud) is built up of several annular segments that are packed together at circumferential and axial junctions. The junctions between these segments need to be sealed in order to minimize leakage and maintain high efficiency. Typically such junctions have slots on the mating edges. Seals are used in the slots, bridging adjacent members, to block off any leakage. Current turbine designs do not have any seals for the curved circumferential junctions. Straight axial junction (dogbone) seals are used in some newer machines. Cloth seals provide the capacity to reduce seal leakage significantly.

\section{Section 2.2.4.14.2 (GTETBS) Steam Gland Brush Seals}

\section{Objective}

Brush seals were developed to minimize steam leakage in the steam gland. Leakage reduction increased the efficiency of the ATS gas turbine. The successful implementation of brush seals in the steam gland also allowed for a reduction in the axial length of the steam gland. The shorter length will result in a manufacturing cost reduction.

\section{Plans}

This task was completed in $4 \mathrm{Q} 97$.

\section{Technology Application}

The brush seals were used in the first machine by nesting the brush seal within the labyrinth seal packings. A slot will be machined in the labyrinth seal to accept the brush seal. On subsequent machines, the steam gland can be shortened to take advantage of improved sealing and reduce the manufacturing cost of the steam gland. 


\section{Section 2.2.5.3.1 (GTFFTB) Bucket TBC Roughness and Spall Characterization}

\section{Objective}

This task quantified the external airfoil heat transfer coefficients associated with the roughness characteristic of TBCs. Special attention was paid to the roughness associated with TBC structure, which can be very different from that of metallic surfaces or coatings.

Typical average roughness measurements made on surfaces cannot fully distinguish between metal finishes, artificial rough surfaces, and applied or polished TBC surfaces. While the measured average roughness values of such surfaces may be the same, the effect on external heat transfer may be quite different due to the specific character of the roughness. This task used CRD's Transient Heat Transfer Cascade to test an airfoil coated with TBC that had been polished to various levels, and assessed the effect of TBC-type roughness.

\section{Plans}

This task was completed in 1 Q97.

\section{Technology Application}

The results from this task were analyzed for consistency among the various roughness levels tested. The results were also compared to other, similar tests run in the same facility that used metallic rough surfaces. If the complete available data show a consistent and clear effect of TBC surface roughness on external heat transfer, these data will be used to determine an equivalent TBC roughness for use in the design heat load predictions on the ATS turbine airfoils. 